\title{
Comparison of white matter integrity between autism spectrum disorder subjects and typically developing individuals: a meta-analysis of diffusion tensor imaging tractography studies
}

Yuta Aoki ${ }^{*}$, Osamu Abe ${ }^{2}$, Yasumasa Nippashi ${ }^{3}$ and Hidenori Yamasue ${ }^{1,4}$

\begin{abstract}
Background: Aberrant brain connectivity, especially with long-distance underconnectivity, has been recognized as a candidate pathophysiology of autism spectrum disorders. However, a number of diffusion tensor imaging studies investigating people with autism spectrum disorders have yielded inconsistent results.

Methods: To test the long-distance underconnectivity hypothesis, we performed a systematic review and metaanalysis of diffusion tensor imaging studies in subjects with autism spectrum disorder. Diffusion tensor imaging studies comparing individuals with autism spectrum disorders with typically developing individuals were searched using MEDLINE, Web of Science and EMBASE from 1980 through 1 August 2012. Standardized mean differences were calculated as an effect size of the tracts.

Results: A comprehensive literature search identified 25 relevant diffusion tensor imaging studies comparing autism spectrum disorders and typical development with regions-of-interest methods. Among these, 14 studies examining regions of interest with suprathreshold sample sizes were included in the meta-analysis. A randomeffects model demonstrated significant fractional anisotropy reductions in the corpus callosum $(P=0.023, n=387$ (autism spectrum disorders/typically developing individuals: $208 / 179)$ ), left uncinate fasciculus $(P=0.011, n=242$ $(117 / 125))$, and left superior longitudinal fasciculus $(P=0.016, n=182(96 / 86))$, and significant increases of mean diffusivity in the corpus callosum $(P=0.006, n=254(129 / 125))$ and superior longitudinal fasciculus bilaterally $(P=0.031$ and 0.011 , left and right, respectively, $n=109(51 / 58))$, in subjects with autism spectrum disorders compared with typically developing individuals with no significant publication bias.

Conclusion: The current meta-analysis of diffusion tensor imaging studies in subjects with autism spectrum disorders emphasizes important roles of the superior longitudinal fasciculus, uncinate fasciculus, and corpus callosum in the pathophysiology of autism spectrum disorders and supports the long-distance underconnectivity hypothesis.
\end{abstract}

Keywords: Autistic disorder, Asperger, Brain, Human, Imaging, Pervasive developmental disorder

\footnotetext{
* Correspondence: yuaoki-tky@umin.ac.jp

'Department of Neuropsychiatry, Graduate School of Medicine, The University of Tokyo, 7-3-1 Hongo, Bunkyo-ku, Tokyo 113-8655, Japan Full list of author information is available at the end of the article
} 


\section{Background}

Atypical brain connectivity has repeatedly been implicated in neuroimaging studies of people with autism spectrum disorders (ASDs) (reviewed in [1]), and suggested as the source of atypical behavioral characteristics found in ASDs. Accumulated evidence from previous postmortem studies [2] and structural and functional magnetic resonance imaging (MRI) studies $[3,4]$ provided the hypothesis that the autistic brain is characterized by long-distance underconnectivity [5-9]. However, it remains unclear which of the major seven longdistance tracts that compose the cortical network in the human brain is disordered [10-13]. These tracts include main association (intrahemispheric) fibers - namely the uncinate fasciculus (UF), cingulum, superior longitudinal fasciculus (SLF), inferior longitudinal fasciculus, inferior frontal occipital fasciculus (IFOF), and fornix - and one commissural (interhemispheric) fiber - namely the corpus callosum (CC).

Currently, diffusion tensor imaging (DTI) is one of the most powerful tools to investigate brain anatomical connectivity, and it can be used to study the orientation and integrity of white matter tracts (reviewed in [14]). This is accomplished by mainly estimating the degree of anisotropy, the property of being directionally dependent, the amount of water molecules using measures including fractional anisotropy (FA), the degree of anisotropy (ranges between 0 that means unrestricted in all directions, and 1 that means restricted in one direction), and the overall displacement of molecules using mean diffusivity (MD) [15].

There are two different principal approaches to evaluating anatomical connectivity from DTI data. The first approach uses a voxel-wise whole brain analysis (WBA), such as voxel-based analysis [16-18] or tract-based spatial statistics (TBSS) [19]. The other approach uses a region-of -interest (ROI) analysis, including using tractography to define the ROI [20-23]. WBA is a powerful strategy for detecting the location of white matter changes in any part of the brain. Although there has been debate regarding how WBA can verify that any given standard space voxel contains data from the same part of the same tract from each and every subject, it is expected that TBSS will resolve these problems [19]. Tractography is a relatively new technology that takes into account the orientation of the diffusion profile to reconstruct the trajectories of the whole fiber bundle and allows quantification of both white matter volume and microstructural organization in specific tracts [14].

Although DTI is a powerful means of testing the disconnectivity hypothesis of ASDs, a number of DTI studies of subjects with ASDs yielded inconsistent results. For example, although some studies reported FA reductions in the $\mathrm{CC}$ of subjects with ASDs [24-26], some reported no significant differences or even higher FA values $[27,28]$ in the CC of subjects with ASDs compared with typically developing (TD) individuals. Further, previous studies have also yielded markedly inconsistent results regarding which tract shows robust differences between people with ASDs and TD individuals. Some studies reported FA differences in the CC of subjects with ASDs [24,27], whereas other reported differences in the inferior frontal occipital fasciculus or in the UF $[24,28]$. These inconsistencies in the direction and location of the reported changes in ASDs may at least partially result from an insufficient number of participants in each study.

To elucidate the tract that is disturbed in people with ASDs, we performed this systematic review and metaanalysis of DTI studies involving individuals with ASDs. As a number of previous neuroimaging studies have consistently reported structural and functional abnormalities in the frontal and temporal lobes (reviewed in $[29,30])$, we hypothesized that long-distance tracts and especially those with connections in the frontal and temporal lobes exhibit consistent abnormalities in people with ASDs. Based on this hypothesis, WBA studies were excluded from the current meta-analysis to specifically focus on the anatomical connectivity of a long-distance tract that is more amenable to evaluation by ROI analyses. The present study thus conducted a meta-analysis of the ROI-based DTI studies.

\section{Methods}

\section{Systematic review}

Data sources

DTI studies that examined the brains of individuals with ASDs and TD individuals were obtained from the computerized databases MEDLINE, Web of Science and EMBASE. The search terms used in the systematic screening were autism, autistic, pervasive developmental disorder, and Asperger, which were also combined with diffusion, tensor, TBSS, tract-based spatial statistics and tractography. Titles and abstracts of the studies were examined to verify whether they could be included. Reference lists of included articles were also examined to search for additional studies to be included.

\section{Study selection}

Studies were included in the initial database if they were brain DTI studies published between 1980 and August 2012 and they examined people with ASDs in comparison with a TD individuals. The studies were then included in the meta-analysis if they utilized a ROI method (for example, manually-defined ROI and tractography). The literature search was performed without language restriction. If the study did not report sufficient data, we emailed the corresponding author to obtain the data. In cases 
where this author did not respond, we excluded the study. Two reviewers (YA and YN) performed the study screenings independently.

\section{Dividing studies into WBA and ROI studies}

In the current review, we performed a systematic screening of DTI studies of subjects with ASDs. A priori defined localized approaches such as manually-placed ROI and tractography studies were then categorized as ROI studies, and were included in the current meta-analyses. However, as voxel-wise voxel-based analysis and TBSS studies are informative, these studies were categorized as WBA studies and are summarized in Table 1.

\section{Meta-analyses \\ Data extraction}

To perform the meta-analyses, we defined the standardized mean differences as the effect size statistic Cohen's $d$, which is calculated as the difference between the mean of the experimental group and that of the comparison group divided by the pooled standard deviation. In the current meta-analyses, the mean FA and MD in autistic individuals were subtracted from those in TD individuals in each ROI, and divided by the pooled standard deviation from both groups. Tracts that were reported in a minimum of three studies were included in the meta-analysis. We followed the guidelines for the Meta-analysis of Observational Studies in Epidemiology [31].

\section{Analyses}

All meta-analyses were performed using Comprehensive Meta-Analysis version 2 (Biostat, Inc., Englewood, NJ, USA). Cohen's $d$ was calculated and used as the effect size. In studies that used multiple ROIs in a single tract (for example, five ROIs in the CC [32]), the weighted average effect size was calculated to reflect the DTI value from the whole tracts rather than part of those tracts [33-35], and to consider differences among values from the same tract. Based on the results of previous studies that have reported asymmetry in major association fibers in subjects with ASD as well as in healthy subjects [36-38], we conducted meta-analyses for the right and left hemispheres independently. A random effects model was adapted for the meta-analysis to minimize potential heterogeneity from factors such as variations in the location of ROIs, magnetic field strength factors, and differences between ROI and tractography approaches. Studies that located their ROIs in the arcuate fasciculus were identified and integrated into analysis of the SLF, since the arcuate fasciculus is considered one of the subcomponents of the SLF [39]. The significance level was set at $P<0.05$.

\section{Assessing between-study heterogeneity}

The $I^{2}$ statistics were calculated by the following formula:

$$
I^{2}=(Q-\mathrm{df}) / Q \times 100
$$

where $Q$ is the chi-squared statistic and $\mathrm{df}$ its degrees of freedom [40]. The $I^{2}$ statistics were employed to examine between-study heterogeneity. Based on previous studies, thresholds for the interpretation of $I^{2}$, which can be misleading but a rough guide to interpretation, suggests that 0 to $50 \%$ represents mild heterogeneity, 50 to $75 \%$ moderate heterogeneity, and 75 to $100 \%$ considerable heterogeneity.

\section{Sensitivity analyses}

To determine the replicability and robustness of the findings, we performed one-study-removed sensitivity analyses in the meta-analyses that revealed significant differences. This analysis was adopted only when the number of included studies equaled or exceeded four, because fewer studies would preclude the conduct of a meta-analysis once one study was removed. In this approach, the meta-analysis is conducted through multiple permutations wherein one of the studies is removed from the dataset. This allows one to determine whether a single study is responsible for a significant result $[41,42]$.

\section{Publication bias}

Publication bias was investigated qualitatively with a funnel plot for each group and brain region. Funnel plot asymmetry was assessed quantitatively by linear regression analysis. A significance level of $P<0.10$ was used to conclude that the studies were heterogeneous [40].

\section{Results}

\section{Systematic review}

\section{Study selection}

The literature search described above yielded 213 studies, of which 46 studies were identified as potential candidates for further screening. Four studies were excluded because they did not compare values between subjects with ASDs and TD individuals. Two studies were excluded because they were tensor-based morphometry studies. One study was removed because of potential overlap of the DTI data with another study from the same group. Seventeen studies were assigned into WBA DTI studies and are summarized in Table $1[18,26,27,43-56]$. Three studies were assigned into both ROI and WBA studies [26,27,43]. Thus, 25 ROI DTI studies were identified as potentially relevant [24-28,32,43,57-74] (Figure 1 and Table 2). 
Table 1 Summary of studies included in the whole brain analysis diffusion tensor imaging group

\begin{tabular}{|c|c|c|c|c|c|c|c|c|c|c|c|c|c|c|c|c|c|c|c|}
\hline \multirow{3}{*}{ Study } & \multicolumn{10}{|c|}{ Demographic character } & \multirow{3}{*}{\multicolumn{2}{|c|}{ Diagnostic tools }} & \multirow{3}{*}{\multicolumn{4}{|c|}{ Medication / comorbidity }} & \multirow[b]{3}{*}{ Tesla } & \multirow[b]{3}{*}{ Number of direction } & \multirow[b]{3}{*}{ NEX } \\
\hline & \multicolumn{4}{|c|}{ ASD } & \multicolumn{6}{|c|}{ TD } & & & & & & & & & \\
\hline & $\overline{N^{a}}$ & Males & Mean age (years) & $\mathrm{IQ}^{\mathbf{b}}$ & $\overline{N^{c}}$ & Males $\Lambda$ & \multicolumn{4}{|c|}{ Mean age (years) $I^{Q^{b}}$} & & & & & & & & & \\
\hline \multicolumn{20}{|c|}{ Whole brain voxel-wise analysis study } \\
\hline Ameis and colleagues [43] & 19 & 16 & 12.4 & 99 & 16 & 8 & \multicolumn{3}{|c|}{12.3} & 101 & DSM & U-IV/ADI-R/AD & & \multicolumn{3}{|c|}{ No/No } & 3 & 12 & 5 \\
\hline Barnea-Goraly and colleagues [44] & 7 & 7 & 14.6 & 101 & 9 & 9 & \multicolumn{3}{|c|}{13.4} & 107 & & ADI-R/ADOS & & \multicolumn{3}{|c|}{$\mathrm{NA} / \mathrm{Na}$} & 3 & 6 & 4 \\
\hline Barnea-Goraly and colleagues [18] & 13 & 11 & 10.5 & 86 & 11 & 9 & \multicolumn{3}{|c|}{9.6} & 120 & & ADI-R/ADOS & & \multicolumn{3}{|c|}{$\mathrm{NA} / \mathrm{No}$} & 1.5 & 6 & 4 \\
\hline Bloemen and colleagues [45] & 13 & 113 & 39 & 110 & 13 & 13 & \multicolumn{3}{|c|}{37} & 115 & ICD- & -10/ADI-R/ADC & & \multicolumn{3}{|c|}{$\mathrm{NA} / \mathrm{No}$} & NA & 4 & NA \\
\hline Bode and colleagues [46] & 27 & 20 & 14.7 & NA & 26 & 17 & \multicolumn{3}{|c|}{14.5} & NA & & ADI-R/ADOS & & \multicolumn{3}{|c|}{ NA/No } & NA & NA & 1 \\
\hline Cheung and colleagues [48] & 13 & 12 & 9.3 & 100 & 14 & 13 & \multicolumn{3}{|c|}{9.9} & 112 & & ICD-10/ADI-R & & \multicolumn{3}{|c|}{$\mathrm{No} / \mathrm{No}$} & 1.5 & 25 & NA \\
\hline Groen and colleagues [49] & 17 & 14 & 14.4 & 98 & 25 & 22 & \multicolumn{3}{|c|}{15.5} & 105 & & ADI-R & & & No/No & & 1.5 & 30 & 4 \\
\hline Jeong and colleagues [50] & 32 & 29 & 439 & NA & 14 & 11 & & 5.61 & & NA & & DSM-IV & & & NA/No & & 3 & 6 & 6 \\
\hline Jou and colleagues [51] & 15 & 15 & 10.9 & NA & 8 & 8 & & 11.5 & & NA & & M-IV/ADI-ADO & & & NA/NA & & 3 & 30 & 3 \\
\hline Jou and colleagues [52] & 10 & 10 & 13.5 & 91 & 10 & 10 & & 13.5 & & 105 & DSM & A-IV/ADI-R/ADC & & & NA/NA & & 1.5 & 6 & 6 \\
\hline Ke and colleagues [53] & 12 & 12 & 8375 & 101 & 12 & 12 & & 9.4 & & 100 & & DSM-IV/ADI-R & & & NA/No & & 1.5 & 15 & 2 \\
\hline Kumar and colleagues [26] & 32 & 29 & 5 & NA & 16 & 12 & & 5.5 & & NA & & DSM-IV & & & NA/No & & 3 & 6 & 6 \\
\hline Noriuchi and colleagues [54] & 7 & 6 & 14 & 93 & 7 & 6 & & 13.4 & & 116 & & DSM-IV & & & NA/NA & & 3 & 32 & NA \\
\hline Sahyoun and colleagues [55] & 12 & 9 & 12.8 & 101 & 12 & 9 & & 13.3 & & 106 & & DSM-IV/ADI-R & & & No/NA & & 3 & 60 & NA \\
\hline Thakkar and colleagues [56] & 12 & 10 & 30 & 116 & 14 & 8 & & 27 & & 114 & DSM & A-IV/ADI-R/ADC & & & Yes/No & & 3 & 60 & NA \\
\hline Weinstein and colleagues [27] & 21 & NA & 3.3 & NA & 26 & NA & & 3.3 & & NA & DSM & A-IV/ADI-R/ADC & & & NA/No & & 1.5 & 15 & 2 \\
\hline & & & & & & Met & thodol & logical & I chara & acter & & & & & & & & & \\
\hline Study & & & & & & & & Value & & & & & & & Multiple & compariso & on corre & ection & \\
\hline & $\mathrm{TE} /$ & TR (ms) & Type of WE & & & Software & e FA & MD & $\mathrm{RD}$ & AD & ADC & Threshold & FWE & FDR & TFCE & Permutati & & Main results & \\
\hline & & & & & & Whole $\mathrm{k}$ & brain & voxel-1 & -wise a & analys & sis stu & udy & & & & & & & \\
\hline Ameis and colleagues [43] & & $0 / 4,100$ & TBSS & & & FSL4.1 & $\circ$ & $\circ$ & $\circ$ & $\circ$ & $\circ$ & $P<0.05$ & $\circ$ & $x$ & $\circ$ & $x$ & & $\begin{array}{l}M D \downarrow \text { in UF, IFOF, CC, SL } \\
\text { in ASD children }\end{array}$ & \\
\hline Barnea-Goraly and colleagues [44] & & $6 / 6,000$ & $\begin{array}{l}\text { Voxel Base } \\
\text { Whole Brai }\end{array}$ & & & SPM99 & $\circ$ & $x$ & $x$ & $x$ & $x$ & $P<0.05$ & $x$ & $x$ & $x$ & $x$ & & $F A \downarrow$ in $C g, U F$, in $A S D$ & \\
\hline Barnea-Goraly and colleagues [18] & & $6 / 6,000$ & TBSS & & & FSL4.1 & $\circ$ & $x$ & $\circ$ & ० & $x$ & $P<0.05$ & $\circ$ & $x$ & $\circ$ & $\circ$ & & $F A \downarrow$ in $C C, S L F$, in ASD & \\
\hline Bloemen and colleagues [45] & 107 & $7 / 15,000$ & $\begin{array}{l}\text { Voxel Base } \\
\text { Whole Brai }\end{array}$ & & & SPM2 & $\circ$ & $\circ$ & $\circ$ & $x$ & $x$ & $P<0.05$ & NA & NA & $x$ & $\circ$ & & $\begin{array}{c}F A \downarrow \text { in IFOF, ILF, CC, SLF, } \\
\text { in ASD }\end{array}$ & \\
\hline Bode and colleagues [46] & & $0 / 8,000$ & TBSS & & & FSL & $\circ$ & $\circ$ & $x$ & $x$ & $x$ & $P<0.0005$ & NA & NA & $x$ & $x$ & & $F A \downarrow$ in IFOF & \\
\hline Cheung and colleagues [48] & 100 & $0 / 10,000$ & $\begin{array}{l}\text { Voxel Base } \\
\text { Whole Brai }\end{array}$ & & & SPM2 & $\circ$ & $x$ & $x$ & $x$ & $x$ & $P<0.0005$ & $x$ & $x$ & $x$ & $x$ & & $F A \downarrow$ in $S L F, F A$, in ASD & \\
\hline
\end{tabular}


Table 1 Summary of studies included in the whole brain analysis diffusion tensor imaging group (Continued)

\begin{tabular}{|c|c|c|c|c|c|c|c|c|c|c|c|c|c|c|}
\hline Groen and colleagues [49] & $93 / 10,100$ & $\begin{array}{l}\text { Voxel Based } \\
\text { Whole Brain }\end{array}$ & SPM5 & 0 & $\bar{\circ}$ & $x$ & $x$ & $x$ & $P<0.05$ & $x$ & ० & $x$ & $x$ & FA $\downarrow$ in SLF, ILF, in ASD \\
\hline Jeong and colleagues [50] & $N A / 1,250$ & Whole Brain Tractography & FSL & $\circ$ & $\circ$ & $x$ & $x$ & $x$ & Various & $x$ & $\circ$ & $x$ & $x$ & $\mathrm{FA} \downarrow$ in, $\mathrm{AF}<\mathrm{UF}, \mathrm{CC}$ in $\mathrm{ASD}$ \\
\hline Jou and colleagues [51] & $85 / 6,200$ & TBSS & FSL & $\circ$ & $x$ & $\circ$ & $\circ$ & $x$ & $P<0.05$ & NA & NA & $\circ$ & $x$ & $F A \downarrow$ in IFOF, SLF, UF, Cg, in ASD \\
\hline Jou and colleagues [52] & $92 / 1,1200$ & $\begin{array}{l}\text { Voxel Based } \\
\text { Whole Brain }\end{array}$ & $\begin{array}{l}\text { Biolmage } \\
\text { Suite }\end{array}$ & $\circ$ & $x$ & $x$ & $x$ & $x$ & $p<0.05$ & $x$ & $x$ & $x$ & $x$ & $\begin{array}{c}F A \downarrow \text { in } C C, C G, S L F, I F O F, I L F, \\
\text { in ASD }\end{array}$ \\
\hline Ke and colleagues [53] & $104.4 / 8,000$ & $\begin{array}{l}\text { Voxel Based } \\
\text { Whole Brain }\end{array}$ & SPMS & $\circ$ & $x$ & $x$ & $x$ & $x$ & $p<0.05$ & $x$ & $x$ & $x$ & $x$ & $\begin{array}{c}\text { No peak coordinates reported } \\
\text { in cortical fibers }\end{array}$ \\
\hline Kumar and colleagues [26] & $79 / 1,0000$ & TBSS & FSL & $\circ$ & $x$ & $x$ & $x$ & $\circ$ & $p<0.05$ & $x$ & $x$ & $x$ & $x$ & $\begin{array}{c}\mathrm{FA} \downarrow \text { in rt UF, IFO, AF, rt Cg, } \\
C C \text { in } A S D\end{array}$ \\
\hline Noriuchi and colleagues [54] & $88 / 7,420$ & $\begin{array}{l}\text { Voxel Based } \\
\text { Whole Brain }\end{array}$ & SPM2 & $\circ$ & $x$ & $x$ & $x$ & $x$ & $p<0.05$ & $\circ$ & $x$ & $x$ & $x$ & $\mathrm{FA} \downarrow$ in $\mathrm{SLF}, \mathrm{CC}, \mathrm{Cg}$, in ASD \\
\hline Sahyoun and colleagues [55] & $84 / 7,980$ & TBSS & FSL & $\circ$ & $\circ$ & $x$ & $x$ & $x$ & $p<0.05$ & NA & NA & $x$ & $\circ$ & $\begin{array}{c}\text { FA个 in bl UF, rt SLF, FA } \downarrow \text { in bl, } \\
\text { SLF, bl FOF in ASD }\end{array}$ \\
\hline Thakkar and colleagues [56] & $82 / 8,400$ & $\begin{array}{l}\text { Voxel Based } \\
\text { Whole Brain }\end{array}$ & FSL & $\circ$ & $x$ & $x$ & $x$ & $x$ & $p<0.05$ & NA & NA & $x$ & $x$ & $\mathrm{FA} \downarrow$ in $\mathrm{Cg}$ in $\mathrm{ASO}$ \\
\hline Weinstein and colleagues [27] & $94 / 1,1000$ & TBSS & FSL 0 & 0 & o & $\circ$ & $\circ$ & $x$ & $p<0.05$ & NA & NA & $\circ$ & $x$ & FA $\uparrow$ in It SLF, bl Cg, CC in ASD \\
\hline
\end{tabular}

${ }^{a}$ Number of ASD participants. ${ }^{b}$ Mean IQ of participants. ${ }^{~ N}$ umber of controls. $A D$ axial diffusivity, $A D C$ apparent diffusion coefficient, $A D I R$ Autism Diagnostic Interview-Revised, $A D O S$ Autism Diagnostic Observation Schedule, ASD autism spectrum, AF arcuate fasciculus, $b /$ bilateral, CC corpus callosum, Cg cingulum, DSM-IV Diagnostic and Statistical Manual of Mental Disorders-IV, FA fractional anisotropy, FDR false discovery rate, FSL FMRIB Software Library, FWE family wise error, ICD-10 International Statistical Classification of Diseases and Related Health Problems-10, IFOF inferior frontal occipital fasciculus, ILF inferior frontal occipital fasciculus, It left, MD mean diffusivity, NA not available, NEX number of excitation, RD radial diffusivity, rt right, SLF superior longitudinal fasciculus, SPM statistical parametric mapping, TBSS tract-based spatial statistics,

TD typically developing, TE echo time, TFCE threshold, free cluster enhancement, TR repetition time, UF uncinate fasciculus, WBA whole brain analysis. 


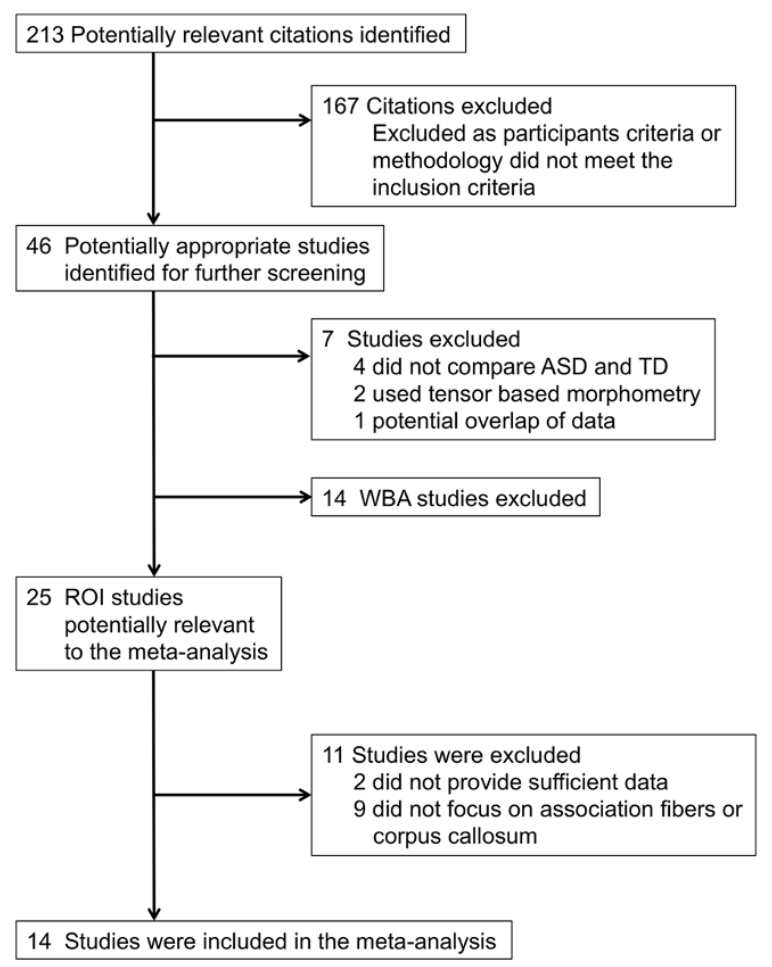

Figure 1 The process used for the study selection. ASD, autism spectrum disorder; ROI, region of interest; TD, typical development; WBA, whole brain analysis.

\section{Characteristics of WBA DTI studies}

Seventeen WBA-DTI studies involved 287 individuals with ASDs and 258 TD individuals. Eight studies utilized a 3 T scanner [26,43,44,50,51,54-56], whereas seven studies used a $1.5 \mathrm{~T}$ scanner $[18,27,47-49,52]$. Two studies did not disclose the strength of the magnetic field $[45,46]$. Eight studies adopted TBSS [18,26,27,43,46,47,51,55]. Thirteen studies identified coordinates where FA was significantly reduced in the $\mathrm{CC}$ or association fibers in individuals with ASDs [18,26,44,45,47-52,54-56], whereas five studies showed coordinates where FA was significantly increased in the $\mathrm{CC}$ or association fibers in individuals with ASDs $[27,46-48,55]$.

\section{Meta-analyses \\ Selection of studies}

Among the 25 candidate ROI DTI studies, two studies were excluded because they did not provide mean and standard deviation metabolite levels; instead of reporting these levels, one reported only $P$ values $[64,65]$ while the other reported only the correlation to autism quotient [66]. These studies were excluded after we emailed the corresponding author to obtain data to calculate the effect size, and the authors did not respond or provide them. In addition, nine studies were excluded because they did not focus on association fibers; instead, they focused on cerebellar fibers $[67,68]$, short distance fibers [69-72], projection fibers [73], and the amygdalofusiform and hippocampo-fusiform pathways [74]. Following these exclusions, 14 studies that examined 330 subjects with ASDs and 313 TD individuals were included in the current meta-analysis [24-28,32,43,57-63].

\section{Meta-analyses}

Corpus callosum Nine studies that recruited 208 subjects with ASDs and 179 TD independent individuals were integrated into the meta-analysis of FA values in the CC [24-27,32,58,60,62,63]. We found significantly low FA values in subjects with ASDs compared with TD individuals $(P=0.023)$. Although the meta-analysis showed considerable heterogeneity, there was no publication bias. For the MD data, five studies with six datasets that examined 129 subjects with ASDs and 125 TD individuals were included in the meta-analysis, and this analysis found significantly increased MD values in subjects with ASDs $(P=0.006)[24,27,43,58,62]$. (Figure 2 and Table 3; see Additional file 1).

Uncinate fasciculus Six studies with six datasets were included in the meta-analysis of 117 subjects with ASDs and 125 TD individuals $[25,26,28,57,62,63]$. The randomeffects model demonstrated a significant FA reduction in the left hemisphere in people with ASDs $(P=0.011)$ (Table 3). The between-study heterogeneity was low and there was no publication bias (see Additional file 1). The analysis demonstrated no significant differences in FA in the right hemisphere between subjects with ASDs and TD individuals $(P=0.216)$. For the MD data, our integrated analysis of three studies with four datasets with 60 subjects with ASDs and 75 TD individuals revealed no significant difference between subjects with ASDs and TD individuals in either hemisphere $(P=0.113$ and 0.790 , left and right, respectively) $[43,57,62]$.

Cingulum Datasets from five studies (involving 101 subjects with ASDs and 109 TD individuals) investigating FA values in the cingulum were included in the analysis [25-27,32,57]. A meta-analysis of these studies showed no significant differences between subjects with ASDs and TD individuals in the left $(P=0.255)$ and right $(P=$ 0.921) hemispheres (Table 3; see Additional file 1 ). Only two studies reported MD in the cingulum in the left and right hemispheres, separately [27,57]. We therefore did not conduct a meta-analysis for MD in the cingulum.

Superior longitudinal fasciculus Five studies that recruited 96 subjects with ASDs and 86 TD individuals were examined in the meta-analysis for FA $[25-27,59,63]$. The random-effects model revealed a significant decrease 
Table 2 Summary of studies included in the regions-of-interest group

\begin{tabular}{|c|c|c|c|c|c|c|c|c|c|c|c|c|}
\hline \multirow{3}{*}{ Study } & \multirow[b]{3}{*}{$N^{\mathrm{a}}$} & \multirow{2}{*}{\multicolumn{2}{|c|}{ ASD group }} & \multicolumn{5}{|c|}{ Demographic character } & \multirow[b]{3}{*}{ Diagnostic tools } & \multirow[b]{3}{*}{$\begin{array}{l}\text { Medication / } \\
\text { comorbidity }\end{array}$} & \multirow[b]{3}{*}{ Tesla } & \multirow[b]{3}{*}{$\begin{array}{l}\text { Number of } \\
\text { direction }\end{array}$} \\
\hline & & & & \multicolumn{3}{|c|}{ TD group } & \multirow[b]{2}{*}{$\begin{array}{l}\text { Mean age } \\
\text { (years) }\end{array}$} & \multirow[b]{2}{*}{$\mathrm{IQ}^{\mathbf{b}}$} & & & & \\
\hline & & Males & $\begin{array}{l}\text { Mean age } \\
\text { (years) }\end{array}$ & $\mathrm{IQ}^{\mathrm{b}}$ & $N^{c}$ & Males & & & & & & \\
\hline \multicolumn{13}{|c|}{ Whole brain voxel-wise analysis study } \\
\hline Alexander and colleagues [24] & 43 & 43 & 16.2 & 107 & 34 & 34 & 16.4 & 113 & $\begin{array}{l}\text { DSM-IV/ICD-10/ADI-R/ADOS- } \\
\text { G }\end{array}$ & Yes/Yes & 3 & 12 \\
\hline Ameis and colleagues [43] & 19 & 16 & 12.4 & 98.5 & 16 & 8 & 12.3 & 101 & DSM-IV/ADI-R/ADOS & No/No & 3 & 12 \\
\hline Beacher and colleagues [58] & 28 & 15 & 32 & NA & 30 & 15 & 30 & NA & DSM-IV & Yes/No & 1.5 & 64 \\
\hline Ben Bashat and colleagues [64] & 17 & NA & NA & NA & NA & NA & 9.6 & NA & DSM-IV/ADI-R/ADOS & NA/NA & 1.5 & 6 \\
\hline Brito and colleagues [32] & 8 & 8 & 9.53 & NA & 8 & 8 & 9.57 & NA & DSM-IV & Yes/No & 1.5 & 12 \\
\hline Catani and colleagues [67] & 15 & 15 & 31 & 109 & 16 & 16 & 35 & 120 & ICD-10/ADI/ADOS & NA/No & 1.5 & 64 \\
\hline Cheon and colleagues [62] & 17 & 17 & 11 & 112 & 17 & 17 & 10.2 & 114 & DSM-IV/ ADI-R/ADOS & Yes/No & 1.5 & 30 \\
\hline Conturo and colleagues [74] & 17 & 14 & 26.5 & 104 & 17 & 14 & 26.1 & 105 & ADI-R/ADOS & Yes/No & 1.5 & 7 \\
\hline Fletcher and colleagues [59] & 10 & 10 & 14.3 & 106 & 10 & 10 & 13.4 & 108 & DSM-IV/ICD-10/ADI-R/ADOS & NA/NA & 3 & 12 \\
\hline Hong and colleagues [60] & 18 & 18 & 8.69 & 105 & 16 & 16 & 9.81 & 106 & DSM-IV/ADI-R & No/No & 1.5 & 15 \\
\hline $\begin{array}{l}\text { Ingalhalikar and colleagues } \\
\text { [69] }\end{array}$ & 45 & 42 & 10.5 & NA & 30 & 14 & 10.3 & NA & NA & NA/NA & 3 & 15 \\
\hline Knaus and colleagues [66] & 14 & 14 & 16.1 & 103 & 20 & 20 & 14.1 & 116 & DSM-IV/ADI-ADOS & NA/No & 3 & 15 \\
\hline Kumar and colleagues [26] & 32 & 29 & 5 & NA & 16 & 12 & 5.5 & $\mathrm{Na}$ & DSM-IV & NA/No & 3 & 6 \\
\hline Langen and colleagues [73] & 21 & 21 & 25.6 & 107 & 22 & 22 & 28.5 & 110 & ICD-10/ADI-R/ADOS & No/No & 3 & 32 \\
\hline Leemans and Jones [78] & 43 & 43 & 16.2 & 108 & 34 & 34 & 16.4 & 113 & $\begin{array}{l}\text { DSM-IV/ICD-10/ADI-R/ADOS- } \\
\text { G }\end{array}$ & NA/No & 3 & 12 \\
\hline Lo and colleagues [25] & 15 & 15 & 15.2 & 108 & 15 & NA & 15 & 111 & DSM-IV/ICD-10/ADI-R & NA/No & 3 & 102 \\
\hline Poustka and colleagues [63] & 18 & 16 & 19.7 & 111 & 18 & 16 & 9.7 & 113 & ICD-10/ADI/ADOS & NA/No & 1.5 & 6 \\
\hline Pugliese and colleagues [57] & 24 & 24 & 23.3 & 105 & 24 & 24 & 25.3 & 121 & ICD-10/ADI-R & No/No & NA & 32 \\
\hline Sahyoun and colleagues [71] & 9 & 7 & 12.8 & 101 & 12 & 9 & 13.3 & 106 & ADIM-IV/ADI-R & No/No & 3 & 60 \\
\hline Shukla and colleagues [65] & 24 & 24 & 5 & NA & 16 & 12 & 5.9 & NA & ADI-R/ADOS & Yes/No & 3 & 15 \\
\hline Sivaswamy and colleagues [68] & 27 & 24 & 5 & NA & 16 & 12 & 5.9 & NA & DSM-IV & Yes/No & 3 & 6 \\
\hline Sundaram and colleagues [72] & 50 & 43 & 4.79 & NA & 16 & 11 & 6.84 & NA & DSM-IVO & Yes/No & 3 & 6 \\
\hline Thomas and colleagues [28] & 12 & 12 & 28.5 & 107 & 18 & 18 & 22.4 & 112 & DSM-IV/ ADI-R/ADOS & NA/No & 3 & 6 \\
\hline Verhoeven and colleagues [61] & 19 & 16 & 13.8 & NA & 33 & 24 & 12.9 & NA & DSM-IV & Yes/No & 3 & 45 \\
\hline Weinstein and colleagues [27] & 22 & NA & 3.2 & NA & 28 & NA & 3.6 & NA & DSM-IV ADI-R/ADOS & NA/Yes & 1.5 & 15 \\
\hline
\end{tabular}


Table 2 Summary of studies included in the regions-of-interest group (Continued)

\begin{tabular}{|c|c|c|c|c|c|c|c|c|c|c|c|c|c|c|c|c|}
\hline \multirow{3}{*}{ Study } & \multicolumn{3}{|c|}{ Methodological character } & \multirow{2}{*}{\multicolumn{5}{|c|}{ Value }} & \multirow{2}{*}{\multicolumn{8}{|c|}{$\mathrm{ROI}$ tract }} \\
\hline & \multirow[b]{2}{*}{ NEX } & \multirow[b]{2}{*}{ TE/TR (ms) } & \multirow[b]{2}{*}{ Type of WBA } & & & & & & & & & & & & & \\
\hline & & & & $\overline{\text { FA }}$ & MD & RD & $A D$ & $\overline{A D C}$ & $\overline{\mathrm{CC}}$ & UF & $\mathrm{Cg}$ & SLF & ILF & IFOF & Fo & $\overline{\mathrm{AF}}$ \\
\hline \multicolumn{17}{|c|}{ Whole brain voxel-wise analysis study } \\
\hline Alexander and colleagues [24] & 4 & $84 / 7,000$ & $\mathrm{ROI}$ & $\circ$ & $\circ$ & $\circ$ & $\circ$ & $x$ & $\circ$ & $x$ & $x$ & $x$ & $x$ & $x$ & $x$ & $x$ \\
\hline Ameis and colleagues [43] & 5 & $80 / 4,100$ & $\mathrm{ROI}$ & $\circ$ & $\circ$ & $x$ & $x$ & $x$ & $\circ$ & $x$ & $\circ$ & $\circ$ & $x$ & $x$ & $x$ & $x$ \\
\hline Beacher and colleagues [58] & NA & $95 / 8,000$ & $\mathrm{ROI}$ & $\circ$ & $x$ & $x$ & $x$ & $x$ & $\circ$ & $x$ & $x$ & $x$ & $x$ & $x$ & $x$ & $x$ \\
\hline Ben Bashat and colleagues [64] & 4 & $128 / 1,800$ & $\mathrm{ROI}$ & $\circ$ & $\circ$ & $x$ & $x$ & $x$ & $\circ$ & $x$ & $\circ$ & $\circ$ & $x$ & $x$ & $x$ & $x$ \\
\hline Brito and colleagues [32] & 3 & $90 / 3,100$ & & $\circ$ & $x$ & $x$ & $x$ & $x$ & $\circ$ & $x$ & $x$ & $x$ & $x$ & $x$ & $x$ & $x$ \\
\hline Catani and colleagues [67] & NA & $107 / 1,500$ & Tractography & $\circ$ & $\circ$ & $x$ & $x$ & $x$ & $\circ$ & $x$ & $\circ$ & $x$ & $\circ$ & $x$ & $x$ & $x$ \\
\hline Cheon and colleagues [62] & 2 & $86 / 6500$ & $\mathrm{ROI}$ & $\circ$ & $\circ$ & $x$ & $x$ & $x$ & $x$ & $x$ & $x$ & $x$ & $x$ & $x$ & $x$ & $x$ \\
\hline Conturo and colleagues [74] & 10 & $94 / 1,51750$ & Tractography & $\circ$ & $\circ$ & $\circ$ & $\circ$ & $x$ & $\circ$ & $\circ$ & $x$ & $x$ & $\circ$ & $x$ & $x$ & $x$ \\
\hline Fletcher and colleagues [59] & 4 & $84 / 700$ & $\mathrm{ROI}$ & $x$ & $x$ & $x$ & $x$ & $x$ & $x$ & $x$ & $x$ & $x$ & $x$ & $x$ & $x$ & $x$ \\
\hline Hong and colleagues [60] & 2 & $104.4 / 8,000$ & $\mathrm{ROI}$ & $\circ$ & $x$ & $x$ & $x$ & $\circ$ & $\circ$ & $x$ & $x$ & $x$ & $x$ & $x$ & $x$ & $x$ \\
\hline Ingalhalikar and colleagues [69] & NA & $70 / 16,900$ & $\mathrm{ROI}$ & $\circ$ & $x$ & $x$ & $x$ & $x$ & $x$ & $x$ & $x$ & $\circ$ & $x$ & $x$ & $x$ & $x$ \\
\hline Knaus and colleagues [66] & NA & N/A & Tractography & $\circ$ & $x$ & $x$ & $x$ & $x$ & $x$ & $x$ & $x$ & $x$ & $x$ & $x$ & $x$ & $\circ$ \\
\hline Kumar and colleagues [26] & 6 & $79 / 10,000$ & Tractography & $\circ$ & $x$ & $x$ & $x$ & $\circ$ & $\circ$ & $\circ$ & $\circ$ & $x$ & $x$ & $\circ$ & $x$ & $\circ$ \\
\hline Langen and colleagues [73] & NA & $107 / 10,000$ & Tractography & $\circ$ & $\circ$ & $\circ$ & $\circ$ & $x$ & $x$ & $x$ & $x$ & $x$ & $x$ & $x$ & $x$ & $x$ \\
\hline Leemans and Jones [78] & 3 & $84 / 7,000$ & $\mathrm{ROI}$ & $\circ$ & $\circ$ & $\circ$ & $\circ$ & $x$ & $x$ & $x$ & $x$ & $x$ & $x$ & $x$ & $x$ & $x$ \\
\hline Lo and colleagues [25] & NA & $142 / 9,100,130 / 9,600$ & $\mathrm{ROI}$ & $\circ$ & $x$ & $x$ & $x$ & $x$ & $\circ$ & $\circ$ & $\circ$ & $x$ & $x$ & $x$ & $x$ & $\circ$ \\
\hline Poustka and colleagues [63] & 15 & $78 / 4,700$ & $\mathrm{ROI}$ & $\circ$ & $x$ & $x$ & $x$ & $x$ & $\circ$ & $\circ$ & $x$ & $\circ$ & $x$ & $x$ & $\circ$ & $x$ \\
\hline Pugliese and colleagues [57] & NA & $107 / 15,000$ & Tractography & $\circ$ & $\circ$ & $x$ & $x$ & $x$ & $x$ & $\circ$ & $\circ$ & $x$ & $\circ$ & $\circ$ & $\circ$ & $x$ \\
\hline Sahyoun and colleagues [71] & $\mathrm{Na}$ & $84 / 7,980$ & $\mathrm{ROI}$ & $\circ$ & $x$ & $x$ & $x$ & $x$ & $x$ & $x$ & $x$ & $x$ & $x$ & $x$ & $x$ & $x$ \\
\hline Shukla and colleagues [65] & 4 & $99.4 / 1,0000$ & $\mathrm{ROI}$ & & $\circ$ & $\circ$ & $\circ$ & $x$ & $\circ$ & $x$ & $x$ & $x$ & $x$ & $x$ & $x$ & $x$ \\
\hline Sivaswamy and colleagues [68] & 6 & $160 / 11000$ & $\mathrm{ROI}$ & $\circ$ & $x$ & $x$ & $x$ & $x$ & $x$ & $x$ & $x$ & $x$ & $x$ & $x$ & $x$ & $x$ \\
\hline Sundaram and colleagues [72] & 6 & $79 / 10,000$ & Tractography & $\circ$ & $x$ & $x$ & $x$ & $\circ$ & $x$ & $x$ & $x$ & $x$ & $x$ & $x$ & $x$ & $x$ \\
\hline Thomas and colleagues [28] & 12 & $82 / 4,900$ & $\mathrm{ROI}$ & $\circ$ & $x$ & $x$ & $x$ & $x$ & $x$ & $\circ$ & $x$ & $x$ & $\circ$ & $\circ$ & $x$ & $x$ \\
\hline Verhoeven and colleagues [61] & 2 & $55 / 11,043$ & Tractography & $\circ$ & $x$ & $x$ & $x$ & $\circ$ & $x$ & $x$ & $x$ & $\circ$ & $x$ & $x$ & $x$ & $x$ \\
\hline Weinstein and colleagues [27] & 2 & $94 / 11,043$ & Tractography & $\circ$ & $\circ$ & $\circ$ & $\circ$ & $x$ & $\circ$ & $x$ & o & $\circ$ & $x$ & $x$ & $x$ & $x$ \\
\hline
\end{tabular}

${ }^{a}$ Number of ASD participants. ${ }^{b}$ Mean IQ of participants. ${ }^{c}$ Number of controls. AD axial diffusivity, $A D C$ apparent diffusion coefficient, $A D I R$ Autism Diagnostic Interview-Revised, $A D O S$ Autism Diagnostic Observation Schedule, AF arcuate fasciculus, ASD autism spectrum disorder, CC corpus callosum, Cg cingulum, DSM-IV Diagnostic and Statistical Manual of Mental Disorders-IV, FA fractional anisotropy, Fo fornix, ICD-10 International Statistical Classification of Diseases and Related Health Problems-10, IFOF inferior frontal occipital fasciculus, ILF inferior longitudinal fasciculus, MD mean diffusivity, NA not available, NEX number of excitation, RD radial diffusivity, $R O I$ region of interest, SLF superior longitudinal fasciculus, $T D$ typically developing, $T E$ echo time, $T R$ repetition time, UF uncinate fasculus. 


\section{Meta-analysis of FA in the CC}

\begin{tabular}{|c|c|c|c|c|c|}
\hline \multirow[t]{2}{*}{ Study name (mean age, SD) } & \multicolumn{5}{|c|}{ Statistics for each study } \\
\hline & $\begin{array}{l}\text { Std diff } \\
\text { in means }\end{array}$ & $\begin{array}{c}\text { Lower } \\
\text { limit }\end{array}$ & $\begin{array}{c}\text { Upper } \\
\text { limit }\end{array}$ & Z-Value & p-Value \\
\hline Weinstein et al. 2011. $(3.2 \pm 1.1)$ & 0.943 & 0.287 & 1.599 & 2.816 & 0.005 \\
\hline al. 2010. (5.0) & 1.264 & -1.916 & -0.613 & -3.805 & 0.000 \\
\hline Hong et al. 2011. (8.7士2.2) & -0.191 & -0.866 & 0.484 & 0.555 & 0.579 \\
\hline Brito et al. 2009. (9.5t & -0.640 & -1.350 & 0.070 & -1.766 & 0.077 \\
\hline 1. $(9.7 \pm 2.1)$ & -0.221 & -0.895 & 0.453 & -0.642 & 0.521 \\
\hline 2011. $(11.0 \pm 2.1)$ & -1.395 & -2.145 & -0.646 & -3.649 & 0.000 \\
\hline Lo et & 55 & -2.597 & -0.913 & -4.084 & 0.000 \\
\hline Alexa & -0.845 & -1.315 & -0.376 & -3.531 & 0.000 \\
\hline I. 2011. (32.0) & -0.064 & -0.579 & 0.451 & -0.244 & 0.807 \\
\hline & -0.5 & -1.0 & 0.081 & -2.275 & \\
\hline
\end{tabular}

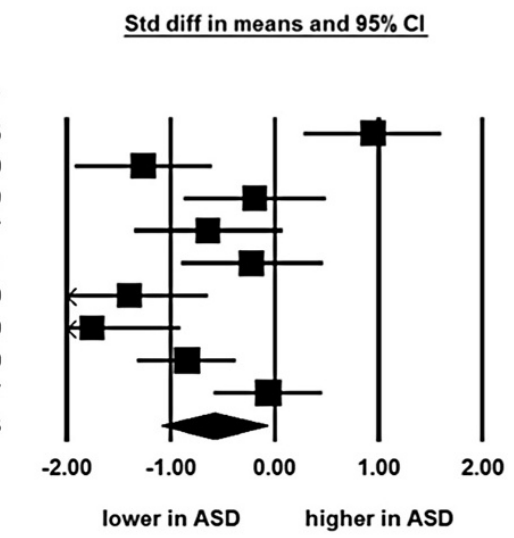

Meta-analyses demonstrated significant FA reduction in the CC in individuals with ASDs.

\section{Meta-analysis of MD in the CC}

\begin{tabular}{|c|c|c|c|c|c|}
\hline \multirow[t]{2}{*}{ Study name } & \multicolumn{5}{|c|}{ Statistics for each study } \\
\hline & $\begin{array}{l}\text { Std diff } \\
\text { in means }\end{array}$ & $\begin{array}{c}\text { Lower } \\
\text { limit }\end{array}$ & $\begin{array}{l}\text { Upper } \\
\text { limit }\end{array}$ & Z-Value & p-Value \\
\hline Weinstein et al. 2011. (3.2 \pm 1.1$)$ & 0.483 & -0.083 & 1.050 & 1.673 & 0.094 \\
\hline Ameis et al. 2011. Children $(10.2 \pm 1.6)$ & 0.645 & -0.234 & 1.523 & 1.439 & 0.150 \\
\hline Cheon et al. 2011. (11.0 \pm 2.1$)$ & 1.104 & 0.383 & 1.826 & 2.999 & 0.003 \\
\hline Ameis et al. 2011. Adolescents (15.3 \pm 1.8$)$ & 0.635 & -0.449 & 1.719 & 1.148 & 0.251 \\
\hline Alexander et al. 2007. (16.2 \pm 6.7$)$ & 0.822 & 0.354 & 1.291 & 3.443 & 0.001 \\
\hline \multirow[t]{2}{*}{ Beacher et al. 2011. (32.0) } & -0.155 & -0.670 & 0.361 & -0.587 & 0.557 \\
\hline & 0.557 & 0.163 & 0.950 & 2.770 & 0.006 \\
\hline
\end{tabular}

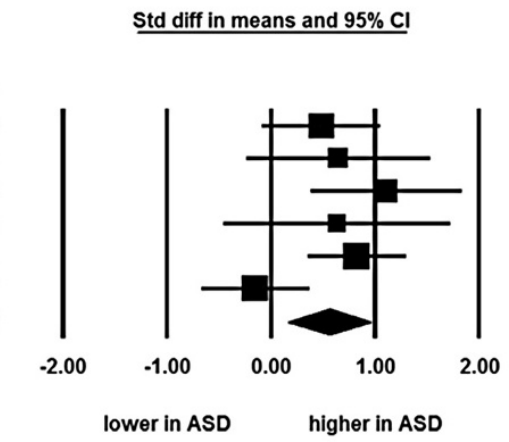

Meta-analysis demonstrated significant MD increase in the CC in individuals with ASDs.

\section{Meta-analysis of FA in the left UF}

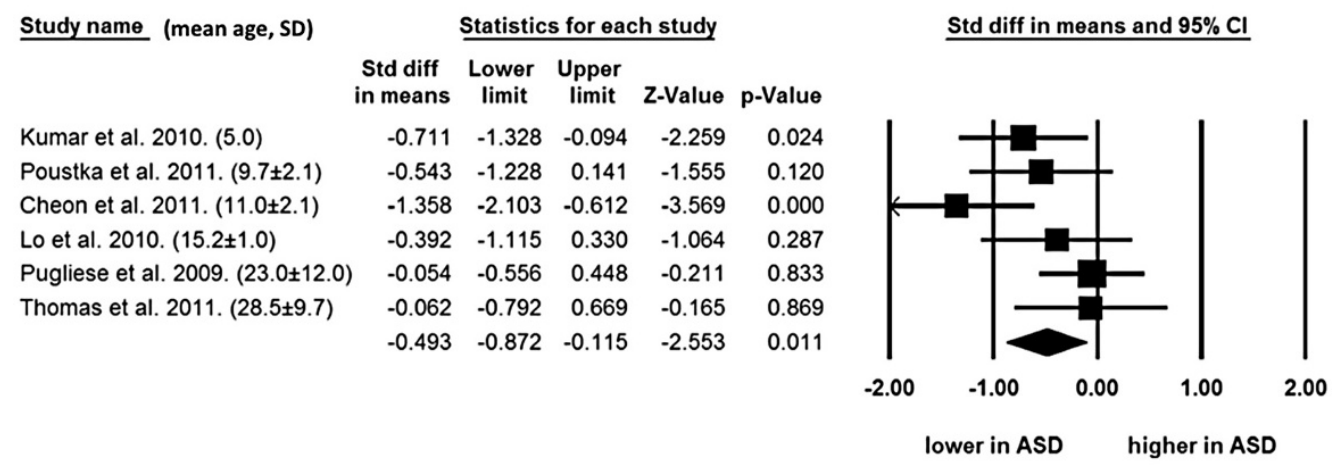

Meta-analysis demonstrated significant FA reduction in the left UF in individuals with ASDs.

Figure 2 (See legend on next page.) 
(See figure on previous page.)

Figure 2 Significant findings from the meta-analyses in the corpus callosum and left uncinate fasciculus. Forest plots of the metaanalyses of fractional anisotropy (FA) (upper), mean diffusivity (MD) in the corpus callosum (CC) (middle) and MD in the left uncinate fasciculus (UF) (lower). Mean and standard deviation (SD) of age of individuals with autism spectrum disorders (ASDs) are demonstrated at the end of each study name. Studies are lined in the order of mean age from the youngest (top) to the oldest (bottom).

in FA values in the left hemisphere $(P=0.016)$. By contrast, a meta-analysis of findings for the right hemisphere demonstrated no significant difference $(P=0.219)$. Three studies with four datasets that involved 51 individuals with ASDs and 58 TD individuals were integrated into the meta-analysis for MD $[27,43,59]$. The results revealed a significant MD increase in the left $(P=0.031)$ and right $(P=0.011)$ hemispheres without publication bias and minimal between-study heterogeneity (Table 3 and Figure 3; see Additional file 1).

Inferior longitudinal fasciculus A meta-analysis of four studies with four datasets with 61 subjects with ASDs and 85 TD individuals did not demonstrate significant FA reductions in the ASD group in the left $(P=0.201)$ and right $(P=0.050)$ hemispheres $[28,32,57,62]$. A metaanalysis for $\mathrm{MD}$ values in this tract could not be conducted because of the limited number of studies. The meta-analysis of FA values demonstrated moderate heterogeneity but no publication bias (Table 3; see Additional file 1).

Inferior frontal occipital fasciculus Three studies with three datasets that involved 68 subjects with ASDs and
76 TD individuals were examined in the meta-analysis $[26,28,57]$. The meta-analysis did not show any significant FA reductions in people with ASDs in either hemisphere ( $P=0.191$ and 0.198 , left and right, respectively) (Table 3; see Additional file 1). MD data were available from only one study.

\section{Sensitivity analyses}

To test the robustness of the significance of findings, we conducted one-study-removed sensitivity analyses of FA values in the CC, left UF and left SLF, and MD values in the CC, left UF, left and right SLF that included more than four studies. For FA values in the CC, five sensitivity analyses out of nine preserved the significant FA reductions, and the remaining four analyses preserved reductions that approached significance (see Additional file 2). One-study-removed sensitivity analysis of FA values in the left UF demonstrated that five sensitivity analyses out of six reached significance whereas the remaining one did not (see Additional file 2). All of the one-dataset-removed sensitivity analyses of MD values in the CC preserved the significance of the higher MD values in subjects with ASDs (Additional file 2). With regard to the left SLF, two out of five one-study-removed

Table 3 Meta-analysis by tract and value

\begin{tabular}{|c|c|c|c|c|c|c|c|c|c|c|c|}
\hline Tract & Laterality & Value & $\begin{array}{l}\text { Number } \\
\text { of dataset }\end{array}$ & $N^{\mathrm{a}}$ & $N^{b}$ & $\begin{array}{l}\text { Lower } \\
95 \% \mathrm{Cl}\end{array}$ & $\begin{array}{l}\text { Upper } \\
95 \% \mathrm{Cl}\end{array}$ & $Z$ value & $P$ value & Heterogeneity $I^{2}$ & Publication bias \\
\hline \multirow[t]{2}{*}{ Corpus callosum } & \multirow[t]{2}{*}{ NA } & FA & 9 & 208 & 179 & -1.087 & -0.081 & -2.275 & 0.023 & 81.91 & 0.541 \\
\hline & & $\mathrm{MD}$ & 6 & 129 & 125 & 0.163 & 0.950 & 2.770 & 0.006 & 53.81 & 0.650 \\
\hline \multirow[t]{4}{*}{ Urinate fasciculus } & \multirow[t]{2}{*}{ Left } & FA & 6 & 117 & 125 & -0.872 & -0.115 & -2.553 & 0.011 & 49.76 & 0.279 \\
\hline & & $\mathrm{MD}$ & 4 & 60 & 75 & -0.148 & 1.300 & 1.584 & 0.113 & 73.96 & 0.682 \\
\hline & \multirow[t]{2}{*}{ Right } & FA & 6 & 116 & 124 & -0.998 & 0.203 & -1.237 & 0.216 & 75.81 & 0.027 \\
\hline & & $\mathrm{MD}$ & 4 & 60 & 75 & 0.123 & -0.410 & 0.963 & 0.790 & 69.11 & 0.636 \\
\hline \multirow[t]{2}{*}{ Cingulum } & Left & FA & 5 & 101 & 109 & -0.846 & 0.224 & -1.139 & 0.255 & 69.80 & 0.633 \\
\hline & Right & FA & 5 & 101 & 109 & -00.475 & 0.525 & 0.099 & 0.921 & 65.94 & 0.857 \\
\hline \multirow{4}{*}{$\begin{array}{l}\text { Superior longitudinal } \\
\text { fasciculus }\end{array}$} & \multirow[t]{2}{*}{ Left } & FA & 5 & 96 & 86 & -0.954 & -0.097 & -2.404 & 0.016 & 48.34 & 0.707 \\
\hline & & MD & 4 & 51 & 58 & 0.062 & 1.256 & 2.163 & 0.031 & 49.66 & 0.950 \\
\hline & \multirow[t]{2}{*}{ Right } & FA & 5 & 92 & 82 & -0.682 & 0.158 & -1.229 & 0.219 & 43.99 & 0.462 \\
\hline & & $\mathrm{MD}$ & 4 & 51 & 58 & 0.140 & 1.100 & 2.534 & 0.011 & 26.11 & 0.499 \\
\hline \multirow{2}{*}{$\begin{array}{l}\text { Inferior longitudinal } \\
\text { fasciculus }\end{array}$} & Left & FA & 4 & 61 & 85 & -1.491 & 0.313 & -1.279 & 0.201 & 83.19 & 0.907 \\
\hline & Right & FA & 4 & 61 & 85 & -0.775 & 0.000 & -1.959 & 0.050 & 20.15 & 0.207 \\
\hline \multirow{2}{*}{$\begin{array}{l}\text { Inferior frontal occipital } \\
\text { fasciculus }\end{array}$} & Left & FA & 3 & 68 & 76 & -0.979 & 0.195 & -1.309 & 0.191 & 63.22 & 0.690 \\
\hline & Right & FA & 3 & 68 & 76 & -0.735 & 0.152 & -1.287 & 0.198 & 37.41 & 0.528 \\
\hline
\end{tabular}

${ }^{a}$ Number of ASD participants. ${ }^{b}$ Number of controls. ASD autism spectrum disorder, $C l$ confidence interval, $F A$ fractional anisotropy, $M D$ mean diffusivity. 


\section{Meta-analysis of FA in the left SLF}

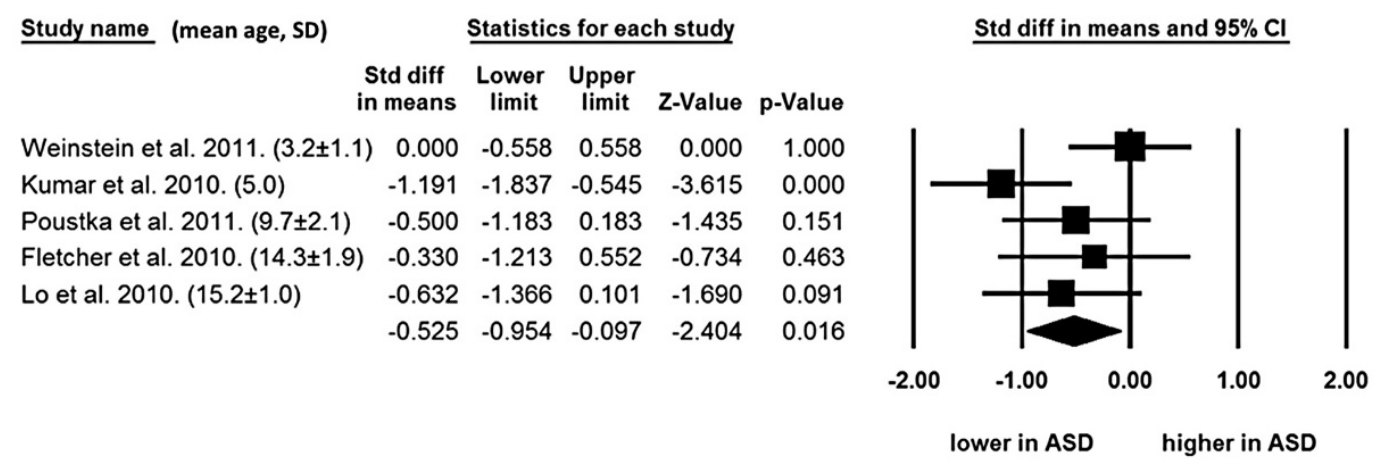

Meta-analyses demonstrated significant FA decrease in the left SLF in individuals with ASDs.

\section{Meta-analysis of MD in the left SLF}

\begin{tabular}{|c|c|c|c|c|c|}
\hline \multirow[t]{2}{*}{ Study name (mean age, SD) } & \multicolumn{5}{|c|}{ Statistics for each study } \\
\hline & $\begin{array}{l}\text { Std diff } \\
\text { in means }\end{array}$ & $\begin{array}{l}\text { Lower } \\
\text { limit }\end{array}$ & $\begin{array}{c}\text { Upper } \\
\text { limit }\end{array}$ & Z-Value & p-Value \\
\hline Weinstein et al. 2011. (3.2 \pm 1.1$)$ & 0.534 & -0.018 & 1.086 & 1.896 & 0.058 \\
\hline Ameis et al. 2011. Children $(10.2 \pm 1.6)$ & 1.123 & 0.202 & 2.044 & 2.389 & 0.017 \\
\hline Fletcher et al. 2010. (14.3 \pm 1.9$)$ & 1.250 & 0.292 & 2.209 & 2.557 & 0.011 \\
\hline \multirow[t]{2}{*}{ Ameis et al. 2011. Adolescents (15.3 \pm 1.8$)$} & -0.333 & -1.399 & 0.732 & -0.613 & 0.540 \\
\hline & 0.659 & 0.062 & 1.256 & 2.163 & 0.031 \\
\hline
\end{tabular}

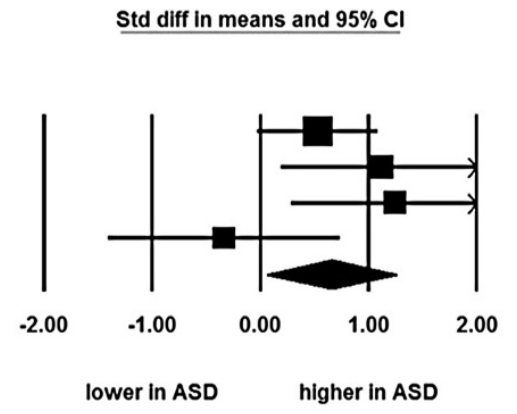

Meta-analysis demonstrated significant MD increase in the left SLF in individuals with ASDs.

\section{Meta-analysis of MD in the right SLF}

\begin{tabular}{|c|c|c|c|c|c|}
\hline \multirow[t]{2}{*}{ Study name } & \multicolumn{5}{|c|}{ Statistics for each study } \\
\hline & $\begin{array}{l}\text { Std diff } \\
\text { in means }\end{array}$ & $\begin{array}{c}\text { Lower } \\
\text { limit }\end{array}$ & $\begin{array}{l}\text { Upper } \\
\text { limit }\end{array}$ & Z-Value & p-Value \\
\hline Weinstein et al. 2011. (3.2 \pm 1.1$)$ & 0.356 & -0.191 & 0.903 & 1.276 & 0.202 \\
\hline Ameis et al. 2011. Children $(10.2 \pm 1.6)$ & 1.453 & 0.490 & 2.415 & 2.959 & 0.003 \\
\hline Fletcher et al. 2010 . (14.3 \pm 1.9$)$ & 0.625 & -0.273 & 1.523 & 1.365 & 0.172 \\
\hline \multirow[t]{2}{*}{ Ameis et al. 2011. Adolescents $(15.3 \pm 1.8)$} & 0.302 & -0.763 & 1.366 & 0.555 & 0.579 \\
\hline & 0.620 & 0.140 & 1.100 & 2.534 & 0.011 \\
\hline
\end{tabular}

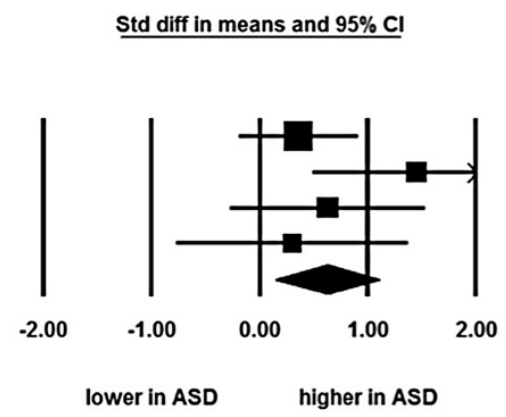

Meta-analysis demonstrated significant MD increase in the right SLF in individuals with ASDs.

Figure $\mathbf{3}$ (See legend on next page.) 
(See figure on previous page.)

Figure 3 Significant findings from the meta-analyses in the superior longitudinal fasciculus. Forest plots of the meta-analyses of fractional anisotropy (FA) (upper) and mean diffusivity (MD) (middle) in the left superior longitudinal fasciculus (SLF) and MD in the right SLF (lower). Mean and standard deviation (SD) of age of individuals with autism spectrum disorders (ASDs) are demonstrated at the end of each study name. Studies are lined in the order of mean age from the youngest (top) to the oldest (bottom).

sensitivity analyses demonstrated a significant FA reduction. Only one out of four one-study-removed sensitivity analyses preserved the significance of the MD increase in the left SLF. Two out of four one-study-removed sensitivity analyses demonstrated a significant MD increase in the right SLF (see Additional file 3).

\section{Discussion}

To our knowledge, this is the first meta-analysis of DTI studies in individuals with ASDs. A comprehensive literature search yielded 25 ROI DTI studies that involved individuals with ASDs. Overall, DTI studies have consistently identified a reduction in anisotropy in subjects with ASDs compared with TD individuals (Tables 1 and 2). Meta-analyses of 14 studies with 330 individuals with ASDs and 313 independent TD individuals demonstrated significantly lower FA values in the CC, left UF and left SLF, and higher MD in the CC and the left and right SLF using random effects models (Figure 4).

We used a random-effects model to minimize the effects of between-study heterogeneity, and only one metaanalysis showed a severe degree of heterogeneity for FA values of the $\mathrm{CC}$ in the current meta-analyses (Table 3). However, previous DTI studies exhibit inherent betweenstudy heterogeneity for other tracts and brain areas besides FA values in the $\mathrm{CC}$. This heterogeneity comes from sources such as differences in data acquisition, data analysis, and subject characteristic among the studies. The current findings should thus be interpreted with caution. Indeed, the accuracy of DTI data is affected by a number of factors [75], such as the signal-to-noise ratio [76], image resolution, image distortion from magnetic susceptibility effects [77], and motion artifacts [78]. Those factors are interrelated and are influenced by the acquisition parameters including the field strength and number of directions, which differ from study to study. As the signal-to-noise ratio strongly affects diffusion tensor measures, some studies conducted several times repetitions of image acquisition to increase the signal-to-noise ratio [79]. However, the number of repetitions used varies between 1 and 15 in previous studies (Tables 1 and 2).

The current systematic review of previous literature showed that FA is the most often investigated DTI value, which ranges from 0 representing maximal isotropic diffusion of water to 1 representing maximal anisotropic diffusion. Although FA values generally reflect cellular membrane integrity, fiber myelination, fiber diameter, localized water content, and directionality [80], the abnormality underlying the reductions in FA values in subjects with ASDs is yet to be specified. As FA reductions may occur as a result of different abnormalities or a combination of abnormalities, and because there is heterogeneity in the ASD population [81], different subpopulations of people with ASDs may display FA reductions from different abnormality. We might possibly have combined FA reductions from different causes in the same meta-analysis. We expect that future study will account for the heterogeneities in people with ASDs by synthesizing an increased number of studies.

In the current study, the meta-analysis demonstrated significantly reduced FA values and increased MD values, which suggests decreased myelination or axonal densities, in the CC of ASDs compared with that of TD individuals. Decreased white matter integrity in the $\mathrm{CC}$ is in line with findings from a previous meta-analysis of MRI studies that

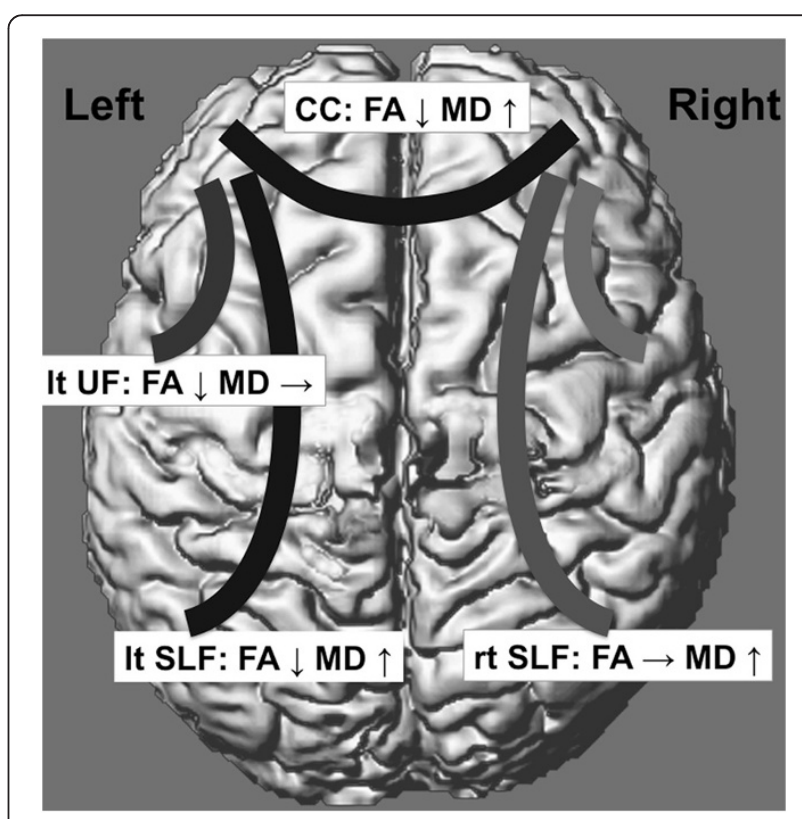

Figure 4 Summary of the main findings. The fractional anisotropy (FA) was significantly decreased, whereas the mean diffusivity (MD) was significantly increased in the corpus callosum (CC) in subjects with autism spectrum disorders (ASDs) compared with TD individuals. The FA was significantly decreased in individuals with ASDs in the left (It) but not in the right (rt) uncinate fasciculus (UF). There was no significant difference in MD values in the UF between subjects with ASDs and TD individuals. The FA was significantly decreased in the left superior longitudinal fasciculus (SLF) but not in the right SLF. The MD was significantly increased in the SLF bilaterally. 
focused on the $\mathrm{CC}$ size and demonstrated a significantly smaller than normal CC in people with ASDs [82]. The $\mathrm{CC}$ provides an integrated interhemispheric white matter bundle and is topographically organized [83,84]. Its disruption may result in many of the sensory, cognitive, and behavioral symptoms observed in children with ASDs [84]. In line with this notion, previous functional MRI studies [85,86] and an EEG study during a REM sleep [87] have reported interhemispheric disconnectivity, suggesting an underlying CC pathophysiology, in people with ASDs compared with TD individuals. The meta-analysis also identified similar pattern of deviations in FA of the left and MD of the bilateral SLF in ASDs. Although the SLF forms the main connection between frontal and occipital regions, this tract has extensive branching in the frontal, parietal and temporal lobes [39]. The tract has been recognized as an important structure for information exchange between Broca's and Wernicke's area [88,89] and may constitute underpinning of abnormal language processing [90], which is frequently observed in people with ASDs.

The current meta-analysis of FA values in the left UF demonstrated a significant reduction in people with ASDs. The importance of this intrahemispheric tract that involves the frontal lobe has also been recognized in the pathophysiology of ASDs [1]. Although there was not enough statistical power and there were no results regarding the axial diffusivity and radial diffusivity to make firm conclusions, the findings of reduced FA in combination with no change in MD may represent microstructural abnormality without gross tissue volume reduction [91]. These significant reductions in FA are concordant with the results of a previous meta-analysis of VBM studies in subjects with ASDs that reported increased white-matter volumes in the UF [92]. The UF is a bundle that connects the medial and lateral orbitofrontal cortices with the anterior portions of the temporal lobe, which are important regions for emotional and attentional processing and reward-related decision making [93-95]. The UF also includes projections into the cortical nuclei of the amygdala [96,97], a limbic region known for its involvement in human social and emotion processing $[98,99]$ and the pathophysiology of ASDs [100-104]. Furthermore, functional MRI studies have repeatedly revealed aberrant functional connectivity between the frontal and temporal lobes in people with ASDs (for example [1]).

The current analyses demonstrated a relatively leftdominant abnormality in the association fibers in individuals with ASDs. The results of the meta-analysis may reflect leftward asymmetry in the brain, which is unrelated to the scanner, brain volume, sex and handedness in TD individuals [105-107] and ASD subjects [36,37]. Brain asymmetry is reported to be a result of typical maturation and essential for typical emotional processing, speech perception, cognition and sensory and motor functions [108-111]. The left-dominant abnormality in the current meta-analysis may be a result of atypical brain maturation in ASD individuals and a potential pathophysiology of disturbances of these functions.

Several limitations of our study should be considered. First, the limited number of included studies in the current meta-analysis did not allow us to perform a meta-regression analysis to test the effects of methodological and clinical differences among the included studies. In addition, there still remains the possibility that meta-analyses did not yield significant difference in other tracts, such as the inferior longitudinal fasciculus, because of the insufficient number of studies included. We therefore cannot emphasize the specificity of abnormalities of the CC, UF and SLF. Second, methodological differences across studies such as in the strength of the magnetic field or the number of excitations and especially regional boundaries of ROIs could have strong effects on DTI findings. In terms of regional boundaries of ROIs, the included studies differ from each other considerably. Although previous meta-analyses also integrated studies employing ROI and those utilizing tractography $[33,34,112]$, the difference in definition of regional borders yielded considerable between-study heterogeneity. Tractography intends to cover the entire fiber, whereas the boundaries of ROIs are determined by the researchers [113]. To reduce the heterogeneity between DTI values from the entire fiber obtained by tractography and one part of fiber gained by ROI, we calculated the mean value of multiple ROIs in the case locating several ROIs within one fiber, although the attempt does not completely diminish the inherent heterogeneity. Third, the clinical characteristics of included study participants differ between studies considerably. The mean age of the participants may be one of the most important confounds because of the abnormal brain growth trajectory in the ASD brain [114-116]. Therefore, although we listed studies included in the meta-analyses in the order of the mean age of participants to enable the reader to qualitatively assess the potential effects of age on effect size, the current metaanalysis could not exclude the possibility that age had effects on FA levels in brain areas such as the CC, UF and SLF. Fourth, although previous studies have reported abnormalities in projection fibers [73] and fibers that connect cerebrum and cerebellum $[67,68]$, and suggested that they potentially underlie the pathophysiology of abnormal behavior in individuals with ASD, we could not conduct meta-analyses because of a lack of sufficient studies. Lastly, as we have reviewed, there are accumulative studies that involved voxel-based analysis to investigate tract abnormality in individuals with ASDs. Although we could not conduct a meta-analysis of these 
studies due to their heterogeneities, in terms of the differences between TBSS and ordinary voxel-wise analysis and small volume correction, there is no doubt that these studies and their meta-analysis could contribute in the future.

\section{Conclusions}

DTI studies involving individuals with ASDs demonstrated significantly low FA values in the CC and left UF and high MD in the CC and SLF bilaterally compared with TD individuals. Although some confounds could not be controlled for because of the limited number of included studies, the current meta-analysis strongly demonstrates that changes in white matter integrity in ASDs are localized in the CC, UF and SLF among association and commissural fibers. The current findings further support the long-distance underconnectivity hypothesis of ASDs.

\section{Additional files}

Additional file 1: a figure showing the one-study-removed sensitivity analysis of the corpus callosum (CC) and left uncinate fasciculus (UF). One-study-removed sensitivity analysis of fractional anisotropy (FA) (upper) and mean diffusivity (MD) (middle) in the CC and MD in the left UF (lower). Mean and standard deviation of age of individuals with ASDs are demonstrated in the end of each study name. Studies are lined in the order of mean age from the youngest (top) to the oldest (bottom)

Additional file 2: a figure showing the one-study-removed sensitivity analysis of the superior longitudinal fasciculus. One-study -removed sensitivity analysis of fractional anisotropy (FA) (upper) and mean diffusivity (MD) (middle) in the left superior longitudinal fasciculus (SLF) and MD in the right SLF (lower). Mean and standard deviation of age of individuals with ASDs are demonstrated in the end of each study name. Studies are lined in the order of mean age from the youngest (top) to the oldest (bottom).

Additional file 3: a figure showing funnel plots of meta-analyses. Funnel plots of the meta-analyses of fractional anisotropy (FA) in the corpus callosum (CC) (a), mean diffusivity (MD) in the CC (b), FA in the left (It) cingulum $(\mathrm{Cg})(\mathrm{c}), \mathrm{FA}$ in the right (rt) $\mathrm{Cg}(\mathrm{d})$, FA in the It uncinate fasciculus (UF) (e), MD in the It UF (f), FA in the rt UF (g), MD in the rt UF (h), FA in the It superior longitudinal fasciculus (SLF) (i), FA in the rt SLF (j), MD in the It SLF (k), MD in the rt SLF (I), FA in the It inferior longitudinal fasciculus (ILF) (m), FA in the rt ILF (n), FA in the It inferior frontal occipital fasciculus (IFOF) (o), and FA in the rt IFOF (p).

\section{Abbreviations \\ ASD: Autism spectrum disorder; CC: Corpus callosum; DTI: Diffusion tensor imaging; FA: Fractional anisotropy; MD: Mean diffusivity; MRI: Magnetic resonance imaging; ROI: Region of interest; SLF: Superior longitudinal fasciculus; TBSS: Tract-based spatial statistics; TD: Typically developing; UF: Uncinate fasciculus; WBA: Whole brain analysis.}

\section{Competing interests}

The authors declare that they have no conflicts of interest.

\section{Authors' contributions}

YA and YN performed the study screenings independently. YA performed all of the data extraction and calculated the effect sizes twice to avoid careless mistakes. YN further performed the data extraction and an independent calculation of the effect sizes. YA, OA and HY wrote the paper. All authors read and approved the final manuscript.

\section{Acknowledgments}

Parts of this study were supported by CREST (Japan Science and Technology Agency) and KAKENHI (MEXT) (22689034 to HY). The authors thank all of the researchers who participated in the studies involved in the current article, especially Dr Ludovico Minati, Dr Wouter B Groen, Dr Ralph-Axel Mueller, Dr Maya Weinstein, Dr Jeong Won Jeong and Dr Cibu Thomas who kindly shared undisclosed data.

\section{Author details}

${ }^{1}$ Department of Neuropsychiatry, Graduate School of Medicine, The University of Tokyo, 7-3-1 Hongo, Bunkyo-ku, Tokyo 113-8655, Japan. ${ }^{2}$ Department of Radiology, Nihon University School of Medicine, Itabashi-ku, Tokyo 173-8610, Japan. ${ }^{3}$ Department of Radiology and Biomedical Engineering, Graduate School of Medicine, The University of Tokyo, 7-3-1 Hongo, Bunkyo-ku, Tokyo 113-8655, Japan. ${ }^{4}$ Japan Science and Technology Agency, CREST, 5 Sanbancho, Chiyoda-ku, Tokyo 102-0075, Japan.

Received: 5 December 2012 Accepted: 8 May 2013

Published: 22 July 2013

\section{References}

1. Vissers ME, Cohen MX, Geurts HM: Brain connectivity and high functioning autism: a promising path of research that needs refined models, methodological convergence, and stronger behavioral links. Neurosci Biobehav Rev 2012, 36:604-625.

2. Vargas DL, Nascimbene C, Krishnan C, Zimmerman AW, Pardo CA: Neuroglial activation and neuroinflammation in the brain of patients with autism. Ann Neurol 2005, 57:67-81.

3. Carper RA, Courchesne E: Localized enlargement of the frontal cortex in early autism. Biol Psychiatry 2005, 57:126-133.

4. Pierce $K$, Haist F, Sedaghat F, Courchesne E: The brain response to personally familiar faces in autism: findings of fusiform activity and beyond. Brain 2004, 127:2703-2716.

5. Courchesne $E$, Pierce $K$ : Brain overgrowth in autism during a critical time in development: implications for frontal pyramidal neuron and interneuron development and connectivity. Int J Dev Neurosci 2005, 23:153-170.

6. Lombardo MV, Chakrabarti B, Bullmore ET, Sadek SA, Pasco G, Wheelwright SJ, Suckling J, Consortium MRCAIMS, Baron-Cohen S: Atypical neural selfrepresentation in autism. Brain 2010, 133:611-624.

7. Murphy DG, Critchley HD, Schmitz N, McAlonan G, Van Amelsvoort T, Robertson D, Daly E, Rowe A, Russell A, Simmons A, Murphy KC, Howlin P: Asperger syndrome: a proton magnetic resonance spectroscopy study of brain. Arch Gen Psychiatry 2002, 59:885-891.

8. Pelphrey KA, Carter EJ: Charting the typical and atypical development of the social brain. Dev Psychopathol 2008, 20:1081-1102

9. McPartland JC, Coffman M, Pelphrey KA: Recent advances in understanding the neural bases of autism spectrum disorder. Curr Opin Pediatr 2011, 23:628-632

10. Bolling DZ, Pitskel NB, Deen B, Crowley MJ, McPartland JC, Kaiser MD, Wyk BC, Wu J, Mayes LC, Pelphrey KA: Enhanced neural responses to rule violation in children with autism: a comparison to social exclusion. Dev Cogn Neurosci 2011, 1:280-294.

11. Ecker C, Suckling J, Deoni SC, Lombardo MV, Bullmore ET, Baron-Cohen S, Catani M, Jezzard P, Barnes A, Bailey AJ, Williams SC, Murphy DG, MRC AIMS Consortium: Brain anatomy and its relationship to behavior in adults with autism spectrum disorder: a multicenter magnetic resonance imaging study. Arch Gen Psychiatry 2012, 69:195-209.

12. Gong G, He Y, Concha L, Lebel C, Gross DW, Evans AC, Beaulieu C: Mapping anatomical connectivity patterns of human cerebral cortex using in vivo diffusion tensor imaging tractography. Cereb Cortex 2009, 19:524-536.

13. Nolte J: The Human Brain. An Introduction to its Functional Anatomy. USA: Mosby; 2008. Philladelphia, PA.

14. Le Bihan D: Looking into the functional architecture of the brain with diffusion MRI. Nat Rev Neurosci 2003, 4:469-480.

15. Bassar PJ, Pierpaoli C: Microstructural and physiological features of tissues elucidated by quantitative-diffusion-tensor MRI. J Magn Reson B 1996, 111:209-219.

16. Ridgway GR, Henley SMD, Rohrer JD, Scahill RI, Warren JD, Fox NC: Ten simple rules for reporting voxel-based morphometry studies. Neurolmage 2008, 40:1429-1435. 
17. Yamasue $H$, Abe $O$, Kasai $K$, Suga M, Iwanami A, Yamada H, Tochigi M, Ohtani T, Rogers MA, Sasaki T, Aoki S, Kato T, Kato N: Human brain structural change related to acute single exposure to sarin. Ann Neurol 2007, 61:37-46.

18. Barnea-Goraly N, Lotspeich LJ, Reiss AL: Similar white matter aberrations in children with autism and their unaffected siblings: a diffusion tensor imaging study using tract-based spatial statistics. Arch Gen Psychiatry 2010, 67:1052-1060

19. Smith SM, Jenkinson M, Johansen-Berg H, Rueckert D, Nichols TE, Mackay CE, Watkins KE, Ciccarelli O, Cader MZ, Matthews PM, Behrens TE: Tractbased spatial statistics: voxelwise analysis of multi-subject diffusion data. Neurolmage 2006, 31:1487-1505.

20. Kubicki M, Niznikiewicz M, Connor E, Nestor P, Bouix S, Dreusicke M, Kikinis $R$, McCarley $R$, Shenton M: Relationship between white matter integrity, attention, and memory in schizophrenia: a diffusion tensor imaging study. Brain Imaging Behav 2009, 3:191-201.

21. Takei $K$, Yamasue $H$, Abe $O$, Yamada $H$, Inoue $H$, Suga M, Sekita $K$, Sasaki $H$ Rogers M, Aoki S, Kasai K: Disrupted integrity of the fornix is associated with impaired memory organization in schizophrenia. Schizophr Res 2008, 103:52-61.

22. Takei $K$, Yamasue $H$, Abe $O$, Yamada $H$, Inoue $H$, Suga M, Muroi M, Sasaki $H$, Aoki S, Kasai K: Structural disruption of the dorsal cingulum bundle is associated with impaired Stroop performance in patients with schizophrenia. Schizophr Res 2009, 114:119-127.

23. Kunimatsu A, Aoki S, Masutani Y, Abe O, Hayashi N, Mori H, Masumoto T, Ohtomo K: The optimal trackability threshold of fractional anisotropy for diffusion tensor tractography of the corticospinal tract. Magn Reson Med Sci 2004, 3:11-17.

24. Alexander AL, Lee JE, Lazar M, Boudos R, DuBray MB, Oakes TR, Miller JN, Lu J, Jeong EK, McMahon WM, Bigler ED, Lainhart JE: Diffusion tensor imaging of the corpus callosum in autism. Neurolmage 2007, 34:61-73.

25. Lo YC, Soong WT, Gau SS, Wu YY, Lai MC, Yeh FC, Chiang WY, Kuo LW, Jaw FS, Tseng WY: The loss of asymmetry and reduced interhemispheric connectivity in adolescents with autism: a study using diffusion spectrum imaging tractography. Psychiatry Res 2011, 192:60-66.

26. Kumar A, Sundaram SK, Sivaswamy L, Behen ME, Makki Ml, Ager J, Janisse J, Chugani HT, Chugani DC: Alterations in frontal lobe tracts and corpus callosum in young children with autism spectrum disorder. Cereb Cortex 2010, 20:2103-2013

27. Weinstein M, Ben-Sira L, Levy Y, Zachor DA, Ben Itzhak E, Artzi M, Tarrasch R, Eksteine PM, Hendler T, Ben BD: Abnormal white matter integrity in young children with autism. Hum Brain Mapp 2011, 32:534-543.

28. Thomas C, Humphreys K, Jung K-J, Minshew N, Behrmann M: The anatomy of the callosal and visual-association pathways in high-functioning autism: a DTI tractography study. Cortex 2011, 47:863-873.

29. Yamasue H, Kuwabara H, Kawakubo Y, Kasai K: Oxytocin, sexually dimorphic features of the social brain, and autism. Psychiatry Clin Neurosci 2009, 63:129-140.

30. Via E, Radua J, Cardoner N, Happé F, Mataix-Cols D: Meta-analysis of gray matter abnormalities in autism spectrum disorder: should Asperger disorder be subsumed under a broader umbrella of autistic spectrum disorder? Arch Gen Psychiatry 2011, 68:409-418.

31. Stroup DF, Berlin JA, Morton SC, Olkin I, Williamson GD, Rennie D, Moher D, Becker BJ, Sipe TA, Thacker SB: Meta-analysis of observational studies in epidemiology: a proposal for reporting. Meta-analysis of observational studies in epidemiology (MOOSE) group. JAMA 2000, 283:2008-2012.

32. Brito AR, Vasconcelos MM, Domingues RC, da Cruz LC H Jr, Rodrigues Lde S, Gasparetto EL, Calçada CA: Diffusion tensor imaging findings in schoolaged autistic children. J Neuroimaging 2009, 19:337-343.

33. Sexton CE, Kalu UG, Filippini N, Mackay CE, Ebmeier KP: A meta-analysis of diffusion tensor imaging in mild cognitive impairment and Alzheimer's disease. Neurobiol Aging 2011, 32:e5-e18.

34. Aoki Y, Inokuchi R, Gunshin M, Yahagi N, Suwa H: Diffusion tensor imaging studies of mild traumatic brain injury: a meta-analysis. J Neurol Neurosurg Psychiatry 2012, 83:870-876

35. Aoki $\mathrm{Y}$, Aoki A, Suwa $\mathrm{H}$ : Reduction of $\mathrm{N}$-acetylaspartate in the medial prefrontal cortex correlated with symptom severity in obsessivecompulsive disorder: meta-analyses of ${ }^{1} \mathrm{H}-\mathrm{MRS}$ studies. Transl Psychiatry 2012, 2:e153.

36. Herbert MR, Ziegler DA, Makris N, Filipek PA, Kemper TL, Normandin נر , Sanders HA, Kennedy DN, Caviness VS Jr: Localization of white matter volume increase in autism and developmental language disorder. Ann Neurol 2004, 55:530-540.

37. Herbert MR, Ziegler DA, Deutsch CK, O'Brien LM, Kennedy DN, Filipek PA Bakardjiev Al, Hodgson J, Takeoka M, Makris N, Caviness VS Jr: Brain asymmetries in autism and developmental language disorder: a nested whole-brain analysis. Brain 2005, 128:213-226.

38. Thiebaut De Schotten M, Ffytche DH, Bizzi A, Dell'Acqua F, Allin M, Walshe M, Murray R, Williams SC, Murphy DG, Catani M: Atlasing location, asymmetry and inter-subject variability of white matter tracts in the human brain with MR diffusion tractography. Neurolmage 2011, 54:49-59.

39. Makris N, Kennedy DN, Mclnerney S, Sorensen AG, Wang R, Caviness VS Jr, Pandya DN: Segmentation of subcomponents within the superior longitudinal fascicle in humans: a quantitative, in vivo, DT-MRI study. Cereb Cortex 2005, 15:854-869.

40. Higgins J, Green S: Cochrane Handbook for Systematic Reviews of Interventions. West Susex, England: John Wiley \& Sons Ltd; 2008

41. Nakao T, Radua J, Rubia K, Mataix-Cols D: Gray matter volume abnormalities in ADHD: voxel-based meta-analysis exploring the effects of age and stimulant medication. Am J Psychiatry 2011, 168:1154-1163.

42. Radua J, Via E, Catani M, Mataix-Cols D: Voxel-based meta-analysis of regional white-matter volume differences in autism spectrum disorder versus healthy controls. Psychol Med 2011, 41:1539-1550.

43. Ameis SH, Fan J, Rockel C, Voineskos AN, Lobaugh NJ, Soorya L, Wang AT, Hollander E, Anagnostou E: Impaired structural connectivity of socioemotional circuits in autism spectrum disorders: a diffusion tensor imaging study. PLoS One 2011, 6:e28044.

44. Barnea-Goraly N, Kwon H, Menon V, Eliez S, Lotspeich L, Reiss AL: White matter structure in autism: preliminary evidence from diffusion tensor imaging. Biol Psychiatry 2004, 55:323-326.

45. Bloemen OJN, Deeley Q, Sundram F, Daly EM, Barker GJ, Jones DK, van Amelsvoort TAMJ, Schmiz N, Robertson D, Murphy KC, Murphy DGM: White matter integrity in Asperger syndrome: a preliminary diffusion tensor magnetic resonance imaging study in adults. Autism Res 2010, 3:203-213.

46. Bode MK, Mattila M-L, Kiviniemi V, Rahko J, Moilanen I, Ebeling H, Tervonen $\mathrm{O}$, Nikkinen $\mathrm{J}$ : White matter in autism spectrum disorders - evidence of impaired fiber formation. Acta Radiol 2011, 52:1169-1174.

47. Cheng Y, Chou K-H, Chen I-Y, Fan Y-T, Decety J, Lin C-P: Atypical development of white matter microstructure in adolescents with autism spectrum disorders. Neurolmage 2010, 50:873-882.

48. Cheung C, Chua SE, Cheung V, Khong PL, Tai KS, Wong TKW, Ho TP, McAlonan GM: White matter fractional anisotrophy differences and correlates of diagnostic symptoms in autism. J Child Psychol Psychiatry 2009, 50:1102-1112.

49. Groen WB, Buitelaar JK, van der Gaag RJ, Zwiers MP: Pervasive microstructural abnormalities in autism: a DTI study. J Psychiatry Neurosci 2011, 36:32-40.

50. Jeong JW, Kumar AK, Sundaram SK, Chugani HT, Chugani DC: Sharp curvature of frontal lobe white matter pathways in children with autism spectrum disorders: tract-based morphometry analysis. Am J Neuroradiol 2011, 32:1600-1606.

51. Jou RJ, Mateljevic N, Kaiser MD, Sugrue DR, Volkmar FR, Pelphrey KA: Structural neural phenotype of autism: preliminary evidence from a diffusion tensor imaging study using tract-based spatial statistics. Am J Neuroradiol 2011, 32:1607-1613.

52. Jou RJ, Jackowski AP, Papademetris $X$, Rajeevan N, Staib LH, Volkmar FR: Diffusion tensor imaging in autism spectrum disorders: preliminary evidence of abnormal neural connectivity. Aust N Z J Psychiatry 2011 45:153-162

53. Ke $X$, Tang $T$, Hong $S$, Hang $Y$, Zou B, Li H, Hang $Y$, Lu Z: White matter impairments in autism, evidence from voxel-based morphometry and diffusion tensor imaging. Brain Res 2009, 1265:171-177.

54. Noriuchi M, Kikuchi Y, Yoshiura T, Kira R, Shigeto H, Hara T, Tobimasa S, Kamio Y: Altered white matter fractional anisotropy and social impairment in children with autism spectrum disorder. Brain Res 2010, 1362:141-149.

55. Sahyoun CP, Belliveau JW, Mody M: White matter integrity and pictorial reasoning in high-functioning children with autism. Brain Cogn 2010, 73:180-188.

56. Thakkar KN, Polli FE, Joseph RM, Tuch DS, Hadjikhani N, Barton JJS, Manoach DS: Response monitoring, repetitive behaviour and anterior cingulate abnormalities in autism spectrum disorders (ASD). Brain 2008, 131:2464-2478. 
57. Pugliese L, Catani M, Ameis S, Dell'Acqua F, Thiebaut De Schotten M, Murphy C, Robertson D, Deeley Q, Daly E, Murphy DG: The anatomy of extended limbic pathways in Asperger syndrome: a preliminary diffusion tensor imaging tractography study. Neurolmage 2009, 47:427-434.

58. Beacher FD, Minati L, Baron-Cohen S, Lombardo MV, Lai MC, Gray MA, Harrison NA, Critchley HD: Autism attenuates sex differences in brain structure: a combined voxel-based morphometry and diffusion tensor imaging study. AJNR Am J Neuroradio/ 2011, 33:83-89.

59. Fletcher PT, Whitaker RT, Tao R, DuBray MB, Froehlich A, Ravichandran C, Alexander AL, Bigler ED, Lange N, Lainhart JE: Microstructural connectivity of the arcuate fasciculus in adolescents with high-functioning autism. Neurolmage 2010, 51:1117-1125.

60. Hong S, Ke X, Tang T, Hang Y, Chu K, Huang H, Ruan Z, Lu Z, Tao G, Liu Y: Detecting abnormalities of corpus callosum connectivity in autism using magnetic resonance imaging and diffusion tensor tractography. Psychiatry Res 2011, 194:333-339.

61. Verhoeven JS, Rommel N, Prodi E, Leemans A, Zink I, Vandewalle E, Noens I, Wagemans J, Steyaert J, Boets B, Van de Winckel A, De Cock P, Lagae L, Sunaert $S$ : Is there a common neuroanatomical substrate of language deficit between autism spectrum disorder and specific language impairment? Cereb Cortex 2011, 10:2263-2271.

62. Cheon KA, Kim YS, Oh SH, Park SY, Yoon HW, Herrington J, Nair A, Koh YJ, Jang DP, Kim YB, Leventhal BL, Cho ZH, Castellanos FX, Schultz RT: Involvement of the anterior thalamic radiation in boys with high functioning autism spectrum disorders: a diffusion tensor imaging study. Brain Res 2011, 1417:77-86.

63. Poustka L, Jennen-Steinmetz C, Henze R, Vomstein K, Haffner J, Sieltjes B: Fronto-temporal disconnectivity and symptom severity in children with autism spectrum disorder. World J Biol Psychiatry 2011, 13:269-280.

64. Ben Bashat D, Kronfeld-Duenias V, Zachor DA, Ekstein PM, Hendler T, Tarrasch R, Even A, Levy Y, Ben Sira L: Accelerated maturation of white matter in young children with autism: $a$ high $b$ value DWI study. Neurolmage 2007, 37:40-47.

65. Shukla DK, Keehn B, Lincoln AJ, Müller R-A: White matter compromise of callosal and subcortical fiber tracts in children with autism spectrum disorder: a diffusion tensor imaging study. J Am Acad Child Adolesc Psychiatry 2010, 49:1269-1278.

66. Knaus TA, Silver AM, Kennedy M, Lindgren KA, Dominick KC, Siegel J, TagerFlusberg $\mathrm{H}$ : Language laterality in autism spectrum disorder and typical controls: a functional, volumetric, and diffusion tensor MRI study. Brain Lang 2010, 112:113-120.

67. Catani M, Jones DK, Daly E, Embiricos N, Deeley Q, Pugliese L, Curran S, Robertson D, Murphy DG: Altered cerebellar feedback projections in Asperger syndrome. Neurolmage 2008, 41:1184-1191.

68. Sivaswamy L, Kumar A, Rajan D, Behen M, Muzik O, Chugani D, Chugani H: A diffusion tensor imaging study of the cerebellar pathways in children with autism spectrum disorder. J Child Neurol 2010, 25:1223-1231.

69. Ingalhalikar M, Parker D, Bloy L, Roberts TPL, Verma R: Diffusion based abnormality markers of pathology: toward learned diagnostic prediction of ASD. Neurolmage 2011, 57:918-927.

70. Lee JE, Bigler ED, Alexander AL, Lazar M, DuBray MB, Chung MK, Johnson M, Morgan J, Miller JN, McMahon WM, Lu J, Jeong EK, Lainhart JE: Diffusion tensor imaging of white matter in the superior temporal gyrus and temporal stem in autism. Neurosci Lett 2007, 424:127-132.

71. Sahyoun CP, Belliveau JW, Soulières I, Schwartz S, Mody M: Neuroimaging of the functional and structural networks underlying visuospatial vs. linguistic reasoning in high-functioning autism. Neuropsychologia 2010 48:86-95

72. Sundaram SK, Kumar A, Makki MI, Behen ME, Chugani HT, Chugani DC Diffusion tensor imaging of frontal lobe in autism spectrum disorder. Cereb Cortex 2008, 18:2659-2665.

73. Langen M, Leemans $A$, Johnston $P$, Ecker $C$, Daly E, Murphy CM, Dell'acqua F, Durston S, Consortium AIMS, Murphy DG: Fronto-striatal circuitry and inhibitory control in autism: findings from diffusion tensor imaging tractography. Cortex 2011, 48:183-193.

74. Conturo TE, Williams DL, Smith CD, Gultepe E, Akbudak E, Minshew NJ: Neuronal fiber pathway abnormalities in autism: an initial MRI diffusion tensor tracking study of hippocampo-fusiform and amygdalo-fusiform pathways. J Int Neuropsychol Soc 2008, 14:933-946.

75. Jones DK, Cercignani M: Twenty-five pitfalls in the analysis of diffusion MRI data. NMR Biomed 2010, 23:803-820.
76. Shi X, Kholmovski EG, Kim S-E, Parker DL, Jeong E-K: Improvement of accuracy of diffusion MRI using real-time self-gated data acquisition. NMR Biomed 2009, 22:545-550.

77. Irfanoglu MO, Walker L, Sarlls J, Marenco S, Pierpaoli C: Effects of image distortions originating from susceptibility variations and concomitant fields on diffusion MRI tractography results. Neurolmage 2012, 61:275-288

78. Leemans A, Jones DK: The B-matrix must be rotated when correcting for subject motion in DTI data. Magn Reson Med 2009, 61:1336-1349.

79. Wang JY, Abdi H, Bakhadirov K, Diaz-Arrastia R, Devous MD: A comprehensive reliability assessment of quantitative diffusion tensor tractography. Neurolmage 2012, 60:1127-1138.

80. Kubicki M, Park H, Westin CF, Nestor PG, Mulkern RV, Maier SE, Niznikiewicz M, Connor EE, Levitt JJ, Frumin M, Kikinis R, Jolesz FA, McCarley RW, Shenton ME: DTI and MTR abnormalities in schizophrenia: analysis of white matter integrity. Neurolmage 2005, 26:1109-1118.

81. Happé F, Ronald A, Plomin R: Time to give up on a single explanation for autism. Nat Neurosci 2006, 9:1218-1220

82. Frazier TW, Hardan AY: A meta-analysis of the corpus callosum in autism. Biol Psychiatry 2009, 66:935-941

83. Abe O, Masutani Y, Aoki S, Yamasue H, Yamada H, Kasai K, Mori H, Hayashi $\mathrm{N}$, Masumoto T, Ohtomo K: Topography of the human corpus callosum using diffusion tensor tractography. J Comput Assist Tomogr 2004, 28:533-539.

84. Paul LK, Brown WS, Adolphs R, Tyszka JM, Richards L, Mukherjee P, Sherr $\mathrm{EH}$ : Agenesis of the corpus callosum: genetic, developmental and functional aspects of connectivity. Nat Rev Neurosci 2007, 8:287-299.

85. Anderson JS, Druzgal TJ, Froehlich A, DuBray MB, Lange N, Alexander AL, Abildskov T, Nielsen JA, Cariello AN, Cooperrider JR, Bigler ED, Lainhart JE: Decreased interhemispheric functional connectivity in autism. Cereb Cortex 2011, 21:1134-1146.

86. Dinstein I, Pierce K, Eyler L, Solso S, Malach R, Behrmann M, Courchesne E: Disrupted neural synchronization in toddlers with autism. Neuron 2011, 70:1218-1225

87. Léveillé C, Barbeau EB, Bolduc C, Limoges E, Berthiaume C, Chevrier E, Mottron L, Godbout R: Enhanced connectivity between visual cortex and other regions of the brain in autism: a REM sleep EEG coherence study. Autism Res 2010, 3:280-285.

88. Paus T, Zijdenbos A, Worsley K, Collins DL, Blumenthal J, Giedd JN, Rapoport $J$, Evans AC: Structural maturation of neural pathways in children and adolescents: in vivo study. Science 1999, 283:1908-1911.

89. Catani M, Allin MP, Husain M, Pugliese L, Mesulam MM, Murray RM, Jones DK: Symmetries in human brain language pathways correlate with verbal recall. Proc Natl Acad Sci U S A 2007, 104:17163-17168.

90. Peters BD, Szeszko PR, Radua J, Ikuta T, Gruner P, Derosse P, Zhang JP, Giorgio A, Qiu D, Tapert SF, Brauer J, Asato MR, Khong PL, James AC, Gallego JA, Malhotra AK: White matter development in adolescence: diffusion tensor imaging and meta-analytic results. Schizophr Bull 2012, 38:1308-1317.

91. Sen PN, Basser PJ: A model for diffusion in white matter in the brain. Biophys J 2005, 89:2927-2938.

92. Rushworth MF, Noonan MP, Boorman ED, Walton ME, Behrens TE: Frontal cortex and reward-guided learning and decision-making. Neuron 2011, 70:1054-1069.

93. Todd RM, Cunningham WA, Anderson AK, Thompson E: Affect-biased attention as emotion regulation. Trends Cogn Sci 2012, 16:365-372.

94. Kennedy DP, Adolphs R: The social brain in psychiatric and neurological disorders. Trends Cogn Sci 2012, 16:559-572.

95. Ebeling $U$, von Cramon D: Topography of the uncinate fascicle and adjacent temporal fiber tracts. Acta Neurochir (Wien) 1992, 115:143-148

96. Hasan KM, Iftikhar A, Kamali A, Kramer LA, Ashtari M, Cirino PT, Papanicolaou AC, Fletcher JM, Ewing-Cobbs L: Development and aging of the healthy human brain uncinate fasciculus across the lifespan using diffusion tensor tractography. Brain Res 2009, 1276:67-76.

97. Schmahmann JD, Pandya DN: Disconnection syndromes of basal ganglia, thalamus, and cerebrocerebellar systems. Cortex 2008, 44:1037-1066.

98. Kleinhans NM, Richards T, Johnson LC, Weaver KE, Greenson J, Dawson G, Aylward E: fMRI evidence of neural abnormalities in the subcortical face processing system in ASD. Neurolmage 2011, 54:697-704.

99. Yamasue $H$, Ishijima M, Abe O, Sasaki T, Yamada H, Suga M, Rogers M, Minowa I, Someya R, Kurita H, Aoki S, Kato N, Kasai K: Neuroanatomy in 
monozygotic twins with Asperger disorder discordant for comorbid depression. Neurology 2005, 65:491-492.

100. Schmahmann JD, Pandya DN, Wang R, Dai G, D'Arceuil HE, de Crespigny AJ, Wedeen VJ: Association fibre pathways of the brain: parallel observations from diffusion spectrum imaging and autoradiography. Brain 2007, 130:630-653.

101. Dalton KM, Nacewicz BM, Alexander AL, Davidson RJ: Gaze-fixation, brain activation, and amygdala volume in unaffected siblings of individuals with autism. Biol Psychiatry 2007, 61:512-520.

102. Mosconi MW, Cody-Hazlett H, Poe MD, Gerig G, Gimpel-Smith R, Piven J: Longitudinal study of amygdala volume and joint attention in 2- to 4-year-old children with autism. Arch Gen Psychiatry 2009, 66:509-516.

103. Nordahl CW, Lange N, Li DD, Barnett LA, Lee A, Buonocore MH, Simon TJ, Rogers S, Ozonoff S, Amaral DG: Brain enlargement is associated with regression in preschool-age boys with autism spectrum disorders. Proc Nati Acad Sci U S A 2011, 108:20195-20200.

104. Takao H, Hayashi N, Ohtomo K: Effect of scanner in asymmetry studies using diffusion tensor imaging. Neurolmage 2011, 54:1053-1062.

105. Takao H, Abe O, Yamasue H, Aoki S, Sasaki H, Kasai K, Yoshioka N, Ohtomo K: Gray and white matter asymmetries in healthy individuals aged 21-29 years: a voxel-based morphometry and diffusion tensor imaging study. Hum Brain Mapp 2011, 32:1762-1773.

106. Takao H, Hayashi N, Ohtomo K: White matter microstructure asymmetry: effects of volume asymmetry on fractional anisotropy asymmetry. Neuroscience 2013, 231:1-12.

107. Hervé PY, Zago L, Petit L, Mazoyer B, Tzourio-Mazoyer N: Revisiting human hemispheric specialization with neuroimaging. Trends Cogn Sci 2013, 17:69-80.

108. McGettigan C, Scott SK: Cortical asymmetries in speech perception: what's wrong, what's right and what's left? Trends Cogn Sci 2012 16:269-276

109. Davidson RJ, Shackman AJ, Maxwell JS: Asymmetries in face and brain related to emotion. Trends Cogn Sci 2004, 8:389-391.

110. Craig AD: Forebrain emotional asymmetry: a neuroanatomical basis? Trends Cogn Sci 2005, 9:566-571.

111. Sexton CE, Mackay CE, Ebmeier KP: A systematic review of diffusion tensor imaging studies in affective disorders. Biol Psychiatry 2009, 66:814-823.

112. Basser PJ, Pajevic S, Pierpaoli C, Duda J, Aldroubi A: In vivo fiber tractography using DT-MRI data. Magn Reson Med 2000, 44:625-632

113. Aoki Y, Kasai K, Yamasue H: Age-related change in brain metabolite abnormalities in autism: a meta-analysis of proton magnetic resonance spectroscopy studies. Transl Psychiatry 2012, 2:e69.

114. Courchesne E, Pierce K, Schumann CM, Redcay E, Buckwalter JA, Kennedy DP, Morgan J: Mapping early brain development in autism. Neuron 2007, 56:399-413

115. Redcay $E$, Courchesne E: When is the brain enlarged in autism? A metaanalysis of all brain size reports. Biol Psychiatry 2005, 58:1-9.

116. Aoki Y, Abe O, Yahata N, Kuwabara H, Natsubori T, Iwashiro N, Takano Y, Inoue H, Kawakubo Y, Gonoi W, Sasaki H, Murakami M, Katsura M, Nippashi Y, Takao H, Kunimatsu A, Matsuzaki H, Tsuchiya KJ, Kato N, Kasai K, Yamasue $\mathrm{H}$ : Absence of age-related prefrontal NAA change in adults with autism spectrum disorders. Transl Psychiatry 2012, 2:e178.

doi:10.1186/2040-2392-4-25

Cite this article as: Aoki et al:: Comparison of white matter integrity between autism spectrum disorder subjects and typically developing individuals: a meta-analysis of diffusion tensor imaging tractography studies. Molecular Autism 2013 4:25.

\section{Submit your next manuscript to BioMed Central and take full advantage of:}

- Convenient online submission

- Thorough peer review

- No space constraints or color figure charges

- Immediate publication on acceptance

- Inclusion in PubMed, CAS, Scopus and Google Scholar

- Research which is freely available for redistribution 